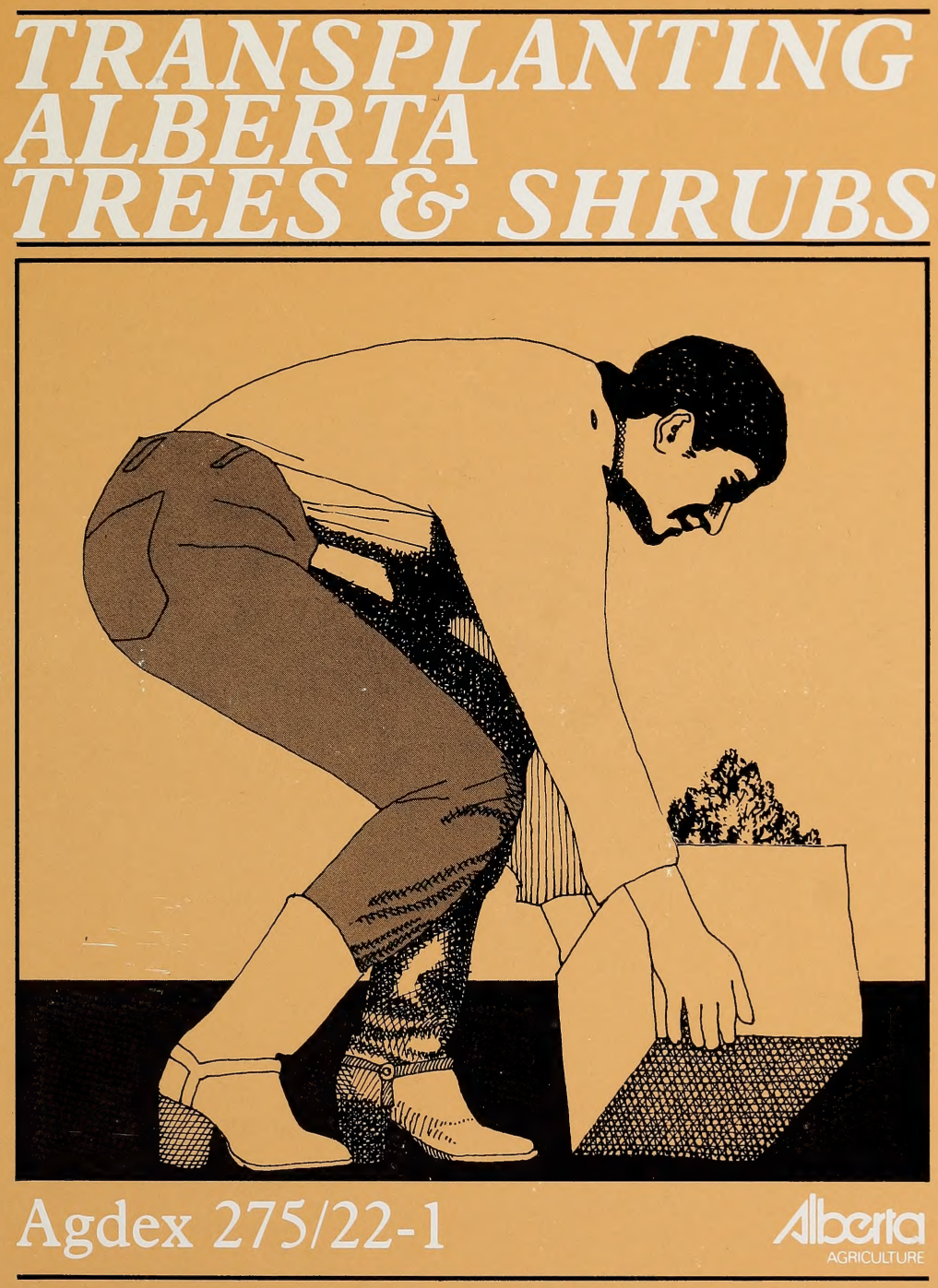


Copies of this publication may be obtained from:

Print Media Branch Alberta Agriculture

$7000-113$ Street

Edmonton, Alberta, T6H 5T6

OR

Alberta Agriculture's district offices 


\title{
TRANSPLANTING ALBERTA TREES AND SHRUBS
}

\author{
G. Grainger \\ Superintendent
}

Alberta Tree Nursery and Horticulture Centre 
Digitized by the Internet Archive in 2016

https://archive.org/details/transplantingalb00grai 


\section{INTRODUCTION}

Transplanting involves the moving of a healthy growing plant from one location to another in such a manner that it will continue to grow. It is concerned not merely with whether a plant lives or dies but that there be a minimum shock and the plant maintains its ability to continue growth and development.

Trees and shrubs are sometimes looked upon as inert objects capable of withstanding any kind of change and condition man can subject them to. It is a fact that plants do very well in some areas and very poorly in others. Like other organisms they respond to favorable conditions and each type varies in its requirements. Most often the conditions into which we want to plant trees and shrubs are less than ideal. It becomes imperative that the transplanting techniques are optimum if the plant is to have a chance at survival.

Transplanting involves three distinct operations - the initial digging, the moving and the replanting at the new site. Maintenance will not be considered a part of transplanting as it is felt to be a separate concern.

The future of the plant, its health, resistance to insects and diseases, beauty, and cost of maintenance are greatly influenced by the way in which the digging, transporting and planting are carried out. Careless transplanting can result in severe injury and even death, despite the use of good soil and a fine plant specimen.

The process of establishing a plant in a new location offers the greatest opportunity for root injury. It can take up to 6 years for the tree or shrub to fully recover.

Every precaution should be taken to protect plants that are on the site before work or disruption begins. Replacing destroyed plants because of unnecessary destruction is expensive, time consuming and reduces the value of the landscape. Every action should be taken to protect branches and the trunk, and to avoid compacting the soil which will aid in destroying the roots. Temporary protection must be erected around the plants to be saved. Excavation and fill over their roots must be avoided. All top soil from the site must be saved for reuse.

In establishing a landscape plan the qualified individual must take the following into account:

1. A wise selection of plant material to suit the site and client needs.

2. To be reasonable in specifying the season of transplanting, particularly in the use of mechanical transplanting equipment.

3. Proper, concise digging instructions must be given.

4. Precise transporting conditions must be given to prevent damage both from mechanical apparatus as well as wind damage.

5. Proper, concise planting instructions at the new site must be given.

Although maintenance is not a part of this publication the plan should include directions for both the short and long term needs of the newly planted stock. All instructions must be clear, precise and understandable by lay people. The instructions must be given by a qualified plants person.

In following the work on the plan many departures from the usual procedure can be made. Each time a change is made the chances for the success of the plant are lessened. As with any process a quick, fast job can be done. A good job takes only a little more time, thought and money than does a crude job, and is always worth the difference. All of the trouble resulting from poor transplanting originates from thinking in terms of minimum requirements; what the tree will stand rather than what it needs.

The most important factor in transplanting is the internal condition of the plant when it is dug. All the lavish precautions such as soil amendments, "root stimulators", top pruning and other practices are unlikely to help an unhealthy plant, and healthy plants do not need them.

\section{PLANT SELECTION (SEE TABLE 1)}

In Alberta we are limited in the kinds and numbers of trees and shrubs available to fit our landscaping needs and desires. The selection process is based on the site and the needs of the owner or client. The homeowner has different needs from the city arborist or utility company. Almost all problems relating to the success of the plants can be anticipated and prevented in the initial planning process (1). Sometimes the site may dictate whether a plant should be transplanted there or not, then the choice of plant material becomes secondary.

A major problem in Alberta is the supply of particular types or varieties of plants for landscape use. By contract growing what planners need, one may get around the problem. Before starting a job the planner should consult the Landscape Alberta Nursery Trades Association for the plant availability list.

With the severe and diverse climate in Alberta the selection of plant material must be based on the plants' ability to survive and grow. Regional differences occur and the planner must be aware of the exact local climate and environmental limitations. Hardy trees should be used where at all possible, and the importation of "exotics" must be limited. The tolerance the plant has to insects and diseases must be considered in the same light as hardiness.

Healthy, well developed plants must be chosen for transplanting. Site visits by the planner to select the best stock is advised. The plant must have well developed tops and roots, showing only normal growth patterns. Abnormal growth, such as spindly twigs, is generally an indication of low ability to survive. The planner must know the plants' characteristics and growth habits before making a choice. Growth habits vary from species to species over the wide and variable geography present in Alberta.

The ability of the plant to be transplanted will further limit selection. The care needed to move plants with a low transplantability may or may not be worth the added costs. 
Generally shrubs transplant better than trees, deciduous trees transplant better than evergreens; container grown plants transplant more readily than plants from the wild. Smaller trees tend to survive better than larger ones. The moving of very large trees, 30 to $45 \mathrm{~cm}$ in diameter at breast height (D.B.H.), can only be accomplished by the most qualified individuals. The costs rise quickly as the size increases.

Soil conditions will cause a variation in root habit. Usually, shallow-rooted tree species move most easily. However, many trees and shrubs with shallow root systems do not withstand drought as well as those developing deeper roots. Root systems develop deeper in sandy, well drained soil than in poorly drained silt or clay soils. Likewise, roots spread more widely in a sandy soil than in a heavy soil.

Figure 1

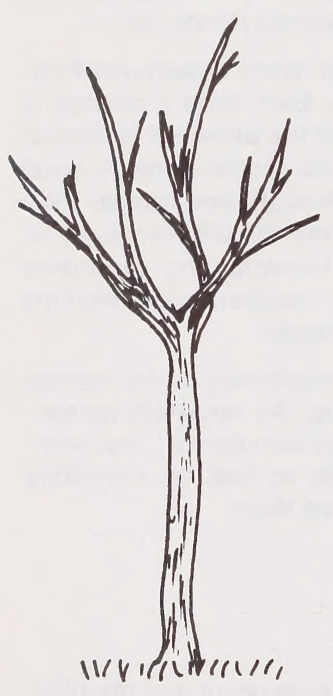

Standard with branching head

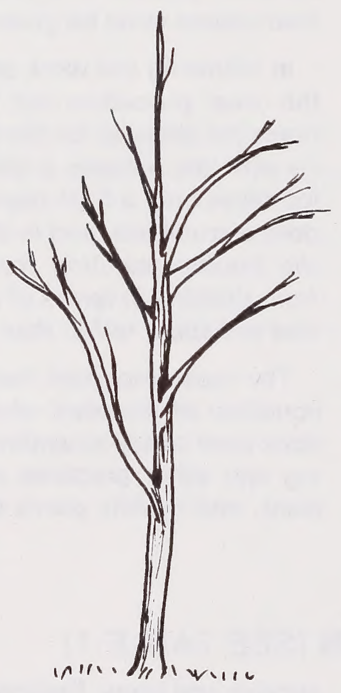

Standard with central leader
Therefore, trees usually can be transplanted more readily with greater assurance of survival from a silt or clay loam soil than from a sandy soil because they have a more compact root system. As a general rule, plants will recover better when transplanted from a heavy to a light soil than from a light to a heavy soil (4).

Certain plants are specific in their soil $\mathrm{pH}$ requirements. To prevent future nutritional problems, those plants with definite soil reaction requirements should only be planted in areas where the soil acidity/alkalinity is within an acceptable range.

The original site can have a bearing on where the plant should be planted. A plant moved from an exposed site will do better when planted in a less exposed site.

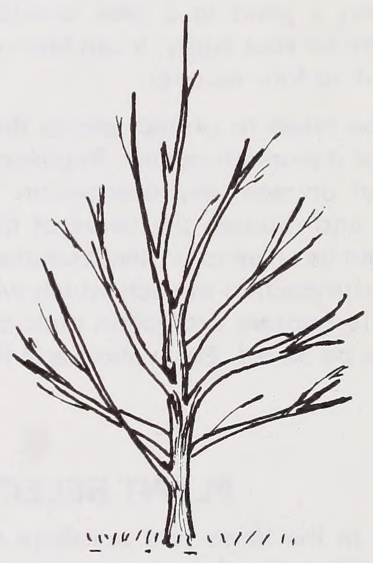

Bush tree

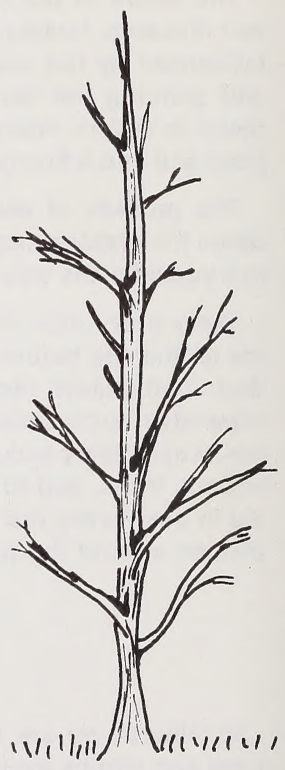

Feathered tree

Figure 1. Forms of trees (Refer to Table 1) 
TABLE 1

SELECTED SPECIFICATIONS ${ }^{1}$

Maximum

Species

Height/

Scientific Name

Spread

Average Retail

No. of

Caliper Range

at Retail

Natural

Height

Form (Figure 1)

DECIDUOUS TREES

\section{Ash}

Black ash

Green ash

Basswood

/Linden

American basswood

Small leaved

basswood

Birch

River birch

Paper birch

European white birch

Cut-leaved weeping birch

Slender weeping birch

Young's weeping birch

\section{Buckeye}

Ohio buckeye

Cherry

Amur cherry

May day

Pincherry

Western chokecherry

Schubert chokecherry

Blackcherry

Flowering

Crabapples

Siberian flowering crab

Pyramidal siberian F.C.

Thunderchild crabapple

Kelsey crabapple

Elm**

Japanese

American

Ascending

Brandon

Manchurian

** because of

\section{Hawthorn}

Chocolate

Fleshy

Toba

Larch

Siberian

\section{Fraxinus}

F. nigra

F. pensylvanica

Tilia

T. americana

T. cordata

Betula

B. fontinalis

B. papyrifera

B. pendula

B. p. 'Gracilis'

B. p. 'Tristis'

B. p. 'Youngi'

\section{Aesculus}

A. glabra

Prunus

P. maackii

P. padus commutata

P. pensylvanica

$P$. virginiana

melanocarpa

P. v. 'Schubert'

$P$. serotina

Malus

M. baccata

$4 m$

M.b. 'Columnaris'

$5 m / 2 m$

M.x. 'Thunderchild'

M.x. 'Kelsey'

$5 m / 4 m$

$4 \mathrm{~m} / 4 \mathrm{~m}$

Ulmus

U. japonica

$U$. americana

U.a. 'Ascending'

U.a. 'Brandon'

U. pumila

$15 \mathrm{~m} / 10 \mathrm{~m}$

1.5-2.0m

$1.5-2.0 \mathrm{~m}$

$1.0-1.5 \mathrm{~m}$

$1.0-1.5 \mathrm{~m}$

1.0-1.5m

$1.0-1.5 \mathrm{~m}$

$6 \mathrm{~m} / 5 \mathrm{~m}$

$12 \mathrm{~m} / 10 \mathrm{~m}$

$20 \mathrm{~m} / 15 \mathrm{~m}$

2.0-2.5m

2.0-2.5m

$15 \mathrm{~m} / 15 \mathrm{~m}$

2.0-2.5m

$15 \mathrm{~m} / 10 \mathrm{~m}$

$12 \mathrm{~m} / 8 \mathrm{~m}$

$1.5-2.0 \mathrm{~m}$

$1.5-2.0 \mathrm{~m}$

\section{Crataegus}

\section{C. cerronis}

C. succulenta

C. mordenensis

"Toba"

Larix

L. sibirica

$10 \mathrm{~m} / 4 \mathrm{~m}$

$1.5-2.0 \mathrm{~m}$

1.5-2.0m

$1.5-2.0 m$

$2.0-2.5 m$
$(7+)$

$(7+)$

$17-25 \mathrm{~mm}$

$17-25 \mathrm{~mm}$

Bush \& Standard Standard

$(7+)$

$(8+)$

$(8+)$

10-15mm

$(8+)$

$(7+)$

$17-25 \mathrm{~mm}$

$(7+)$

$14-20 \mathrm{~mm}$

$(6+)$

$(7+)$

$(7+)$

$(7+)$

$(5+)$

$(5+)$

$(5+)$

$(5+)$

$(5+)$

$(5+)$

$(5+)$

$(5+)$

$(8+)$

$(8+)$

$(8+)$

$(7+)$

$(7+)$

$(7+)$

$(7+)$

$17-25 \mathrm{~mm}$

$(7+)$

$(8+)$

$17-25 \mathrm{~mm}$
$14-20 \mathrm{~mm}$

$14-20 \mathrm{~mm}$

$10-15 \mathrm{~mm}$

$14-20 \mathrm{~mm}$

$8-10 \mathrm{~mm}$

$10-15 \mathrm{~mm}$

$10-15 \mathrm{~mm}$

$10-15 \mathrm{~mm}$

$8-15 \mathrm{~mm}$

8-15mm

$8-15 \mathrm{~mm}$

$8-15 \mathrm{~mm}$

$8-15 \mathrm{~mm}$

$8-15 \mathrm{~mm}$

8-15mm

$8-10 \mathrm{~mm}$

$17-25 \mathrm{~mm}$

$15-20 \mathrm{~mm}$

Bush \& Standard

Standard

Bush

Bush \& Standard

Weeping

Weeping

Weeping

Weeping

Bush \& Standard

Bush

Bush

Bush/Standard

Bush/Standard

Bush/Standard

Bush/Standard

$12-25 \mathrm{~mm}$

$17-25 \mathrm{~mm}$

$17-25 \mathrm{~mm}$

$15-20 \mathrm{~mm}$

$15-20 \mathrm{~mm}$

Bush/Standard

Bush

Bush

\section{Standard}

Standard

branching head

Bush/Standard

Standard

Standard/Bush

Standard

Standard

Bush/Standard 
SELECTED SPECIFICATIONS ${ }^{1}$

Maximum

Height/

Average Retail

No. of

Caliper Range

at Retail

Natural

Species

Scientific Name

Spread

Height

Branches $^{2}$

Height

Form (Figure 1)

DECIDUOUS TREES

Lilac

Japanese Tree

\section{Maple}

Manitoba

Tartarian

Mountain Ash

American

European

Russian

Showy

Green's

Oak

Bur

Russian Olive

Russian

Siberian Pea Tree

Sutherland

siberian

Pear

Ussurian

Poplar,

Cottonwood

Silver

Balsam

Cottonwood

Swedish columnar aspen

Griffin

Brown-twig

Northwest

Brooks \#6

Willow

Sharpleaf

Golden

Siberian white

Laurel leaved

French pussy

Dropmore

weeping

\section{Syringa}

S. amurensis japonica

Acer
A. negundo

A. tataricum

\section{Sorbus}

S. americana

S. aucuparia

S. a. rossica

S. decora

S. scopulina

Quercus

Q. macrocarpa

Eleagnus

E. angustifolia

Caragana

C. arborescens

'Sutherland'

Pyrus

P. ussuriensis

Populus

P. alba pyramidalis $\quad 12 \mathrm{~m} / 2 \mathrm{~m}$

$20 \mathrm{~m} / 12 \mathrm{~m}$

P. balsamifera

P. deltoides

$30 \mathrm{~m} / 20 \mathrm{~m}$

P. tremula erecta

P.x. 'Griffin'

$12 \mathrm{~m} / 6 \mathrm{~m}$

$10 \mathrm{~m} / 5 \mathrm{~m}$

P. tristis

P.x. 'Northwest'

P.x. 'Brooks \#6'

Salix
S. acutifolia
S. alba vitellina
S. a. sericea
S. pentandra
S. caprea
S.x. 'Dropmore
Weeping'

$12 m / 6 m$

$20 \mathrm{~m} / 15 \mathrm{~m}$

$20 \mathrm{~m} / 15 \mathrm{~m}$

$10 \mathrm{~m} / 6 \mathrm{~m}$

$15 \mathrm{~m} / 15 \mathrm{~m}$

$14 \mathrm{~m} / 6 \mathrm{~m}$

$15 \mathrm{~m} / 15 \mathrm{~m}$

$5 \mathrm{~m} / 3 \mathrm{~m}$

$5 m / 5 m$ 1.0-1.5m

2.0-2.5m

1.0-1.5m

2.0-2.5m

2.0-2.5m

2.0-2.5m

1.5-2.0m

$1.5-2.0 \mathrm{~m}$

$1.5-2.0 \mathrm{~m}$

$1.5-2.0 m$

$1.5-2.0 m$

1.5-2.0m

$(6+)$

$(8+)$
$(8+)$

$(8+)$

$(7+)$

$(7+)$

$(6+)$

$(6+)$

$15-20 \mathrm{~mm}$

$15-20 \mathrm{~mm}$

$15-20 \mathrm{~mm}$

$15-20 \mathrm{~mm}$

$15-20 \mathrm{~mm}$

$15-20 \mathrm{~mm}$

$17-25 \mathrm{~mm}$

$10-15 \mathrm{~mm}$

$17-25 \mathrm{~mm}$

$2.0-2.5 m$

2.0-2.5m

2.0-2.5m

2.0-2.5m

2.0-2.5m

2.0-2.5m

2.5-3.0m

2.5-3.0m

1.5-2.0m

$1.5-2.0 \mathrm{~m}$

$1.5-2.0 \mathrm{~m}$

$1.5-2.0 \mathrm{~m}$

$1.0-1.5 \mathrm{~m}$

$1.0-1.5 \mathrm{~m}$

$(8+)$

$(8+)$

$(8+)$

$(8+)$

$(8+)$

$(8+)$

$(8+)$

$(8+)$

$$
\begin{aligned}
& (6+) \\
& (6+) \\
& (6+) \\
& (6+) \\
& (5+) \\
& (5+)
\end{aligned}
$$

$15-20 \mathrm{~mm}$

$15-20 \mathrm{~mm}$

$17-25 \mathrm{~mm}$

$17-25 \mathrm{~mm}$

20-25mm

$17-25 \mathrm{~mm}$

20-25mm

20-25mm

$10-15 \mathrm{~mm}$

$10-15 \mathrm{~mm}$

$10-15 \mathrm{~mm}$

$10-15 \mathrm{~mm}$

$8-12 \mathrm{~mm}$

$8-12 \mathrm{~mm}$
Bush/Standard

Bush/Standard

Bush/Standard

Standard

Standard

Standard/Bush

Standard

Bush/Standard

Standard/Bush

Bush/Standard

Feathered upright

Standard/Bush

Standard upright

Standard/Bush

Standard/Bush

Standard

Upright

Standard

Upright

Standard

Upright

Standard

Standard

Bush/Standard

Bush/Standard

Bush/Standard

Bush/Standard

Bush/Standard

Standard/

Weeping
Maximum

Height/

Spread

$\begin{array}{cc}\text { Average Retail } & \begin{array}{c}\text { Average } \\ \text { Retail } \\ \text { Height }\end{array} \\ \text { Spread }\end{array}$
Caliper Range at Retail Height

Natural Form (Figure 1)

\section{CONIFEROUS TREES}

\section{Arbor-Vitae}

White cedar

Douglas Fir

Rocky Mtn.

\section{Thuja}

$T$. occidentalis

$8 m / 2 m$

$.75-1.0 m$

$15-25 \mathrm{~cm}$

$20-27 \mathrm{~mm}$

Upright/Standard

$P$. menziesii glauca

$15 \mathrm{~m} / 5 \mathrm{~m}$

$1.0-1.25 \mathrm{~m}$

$40-60 \mathrm{~cm}$

25-35mm

Standard 


\begin{tabular}{|c|c|c|c|c|c|c|}
\hline Species & Scientific Name & $\begin{array}{c}\text { Maximum } \\
\text { Height/ } \\
\text { Spread }\end{array}$ & $\begin{array}{c}\text { Average Retail } \\
\text { Height }\end{array}$ & $\begin{array}{c}\text { No. of } \\
\text { Branches }^{2}\end{array}$ & $\begin{array}{c}\text { Caliper Range } \\
\text { at Retail } \\
\text { Height }\end{array}$ & $\begin{array}{c}\text { Natural } \\
\text { Form (Figure 1) }\end{array}$ \\
\hline \multicolumn{7}{|c|}{ CONIFEROUS TREES } \\
\hline $\begin{array}{l}\text { Pine } \\
\text { Bristlecone }\end{array}$ & $\begin{array}{l}\text { Pinus } \\
\text { P. aristata }\end{array}$ & $6 m / 3 m$ & $.75-1.0 m$ & $30-50 \mathrm{~cm}$ & $20-25 \mathrm{~mm}$ & $\begin{array}{l}\text { Spreading/ } \\
\text { Standard }\end{array}$ \\
\hline Jack & P. banksiana & $12 m / 6 m$ & $1.0-1.25 \mathrm{~m}$ & $50-65 \mathrm{~cm}$ & $25-35 \mathrm{~mm}$ & Standard/Bush \\
\hline Swiss stone & P. cembra & $10 m / 3 m$ & $1.0-1.25 \mathrm{~m}$ & $50-65 \mathrm{~cm}$ & $25-35 \mathrm{~mm}$ & Standard/Bush \\
\hline Lodgepole & P. contorta latifolia & $12 m / 3 m$ & $1.0-1.25 \mathrm{~m}$ & $50-65 \mathrm{~cm}$ & $25-35 \mathrm{~mm}$ & Standard \\
\hline Mugo & P. mugo rostrata & $6 m / 3 m$ & $.75-1.0 m$ & $30-50 \mathrm{~cm}$ & $20-25 \mathrm{~mm}$ & $\begin{array}{l}\text { Spreading/ } \\
\text { Standard }\end{array}$ \\
\hline Austrian & $P$. nigra & $12 \mathrm{~m} / 6 \mathrm{~m}$ & $1.0-1.25 \mathrm{~m}$ & $50-65 \mathrm{~cm}$ & $25-35 \mathrm{~mm}$ & Standard/Bush \\
\hline Bull & P. ponderosa & $12 \mathrm{~m} / 6 \mathrm{~m}$ & $1.0-1.25 \mathrm{~m}$ & $50-65 \mathrm{~cm}$ & $25-35 \mathrm{~mm}$ & Standard \\
\hline Eastern white & P. strobus & $12 \mathrm{~m} / 6 \mathrm{~m}$ & $1.0-1.25 \mathrm{~m}$ & $50-65 \mathrm{~cm}$ & $25-35 \mathrm{~mm}$ & Standard \\
\hline Scots & P. sylvestris & $12 \mathrm{~m} / 6 \mathrm{~m}$ & $1.0-1.25 \mathrm{~m}$ & $50-65 \mathrm{~cm}$ & $25-35 \mathrm{~mm}$ & Standard/Bush \\
\hline Spruce & Picea & & & & & \\
\hline Norway & P. abies & $15 \mathrm{~m} / 5 \mathrm{~m}$ & $1.0-1.25 \mathrm{~m}$ & $40-60 \mathrm{~cm}$ & $18-24 \mathrm{~mm}$ & Standard \\
\hline Engelman & P. englemannii & $12 m / 15 m$ & $1.0-1.25 \mathrm{~m}$ & $40-60 \mathrm{~cm}$ & $18-24 \mathrm{~mm}$ & Standard \\
\hline White & P. glauca & $15 \mathrm{~m} / 5 \mathrm{~m}$ & $1.0-1.25 \mathrm{~m}$ & $40-60 \mathrm{~cm}$ & $16-20 \mathrm{~mm}$ & Standard \\
\hline Black Hills & P. g. densata & $10 m / 3 m$ & $1.0-1.25 \mathrm{~m}$ & $40-60 \mathrm{~cm}$ & $18-24 \mathrm{~mm}$ & Standard \\
\hline Serbian & P. omorika & $10 \mathrm{~m} / 4 \mathrm{~m}$ & $1.0-1.25 \mathrm{~m}$ & $40-60 \mathrm{~cm}$ & $18-24 \mathrm{~mm}$ & Standard \\
\hline Colorado & P. pungens & $12 m / 5 m$ & $1.0-1.25 \mathrm{~m}$ & $40-60 \mathrm{~cm}$ & $20-25 \mathrm{~mm}$ & Standard \\
\hline Colorado blue & P.p. glauca & $1.0-1.25 \mathrm{~m}$ & $1.0-1.25 \mathrm{~m}$ & $40-60 \mathrm{~cm}$ & $20-25 \mathrm{~mm}$ & Standard \\
\hline Hoopsi blue & P. p. 'Hoopsii' & $12 m / 2 m$ & $1.0-1.25 \mathrm{~m}$ & $40-60 \mathrm{~cm}$ & $20-25 \mathrm{~mm}$ & Standard \\
\hline
\end{tabular}

(1) The trees and shrubs list as found in the Alberta Horticultural Guide, with a specification of the size generally for sale in Alberta. The size and specifications are for a well formed and cared for speciman.

(2) Based on American Standards for Nursery Stock, 1973. American Association of Nurserymen, Inc.

\section{Coniferous Shrubs}

The height range is given in the Alberta Horticultural Guide. The plants generally available have a $20-35 \mathrm{~cm}$ spread.

\section{Deciduous Shrubs}

The material is generally available or sold by height size or number of canes. Plants of $4-5$ canes, $30-60 \mathrm{~cm}$ in height transplant best.

Larger or smaller plants in all classifications are available. It is the intent to give a realistic view of height, spread, trunk diameter and condition in relation to the plants' ability to survive and grow when moved.

A green ash 6 metres tall with a stem diameter of 15 millimetres could not survive well in an open wind-swept situation.

Tree species vary greatly in their reactions to being moved. As a rule, trees with compact, fibrous root systems are moved with greater ease and less shock than are those with large taproots or long scraggly root systems. Among the trees that are most easily moved and that appear to suffer least shock are ash, elm, linden, maple, poplar, and willow. Trees moved with greater difficulty are apple, buckeye, and spruce. Those moved with the greatest of difficulty are birch, hawthorn, pine and species of oak.

\section{SEASON FOR TRANSPLANTING}

Most plants can be successfully transplanted almost any time that the soil is not frozen. Extraordinary precautions are necesary in the summer months or when the plant is in full growth. Plants to be moved in the summer or when in full growth should be moved by a well qualified horticulturist who is totally aware of the problems and conditions. Plants with a fleshy root system, such as dogwood, oak, etc. are more successfully moved in the early spring than in the fall. A dry fall followed by a cold and dry winter results in the death of a good proportion of fall transplanted plants. Summer transplanting requires the soil to be at its maximum water holding capacity.
Best success in transplanting evergreens follows transplanting done in August or early September. Spring transplanting is better than fall when the plants are subjected to high winds. The highest success in transplanting evergreens is attained when the soil is cool and root growth can continue. In general, evergreens as a group are best moved earlier in the fall and later in the spring than deciduous trees. Evergreen root systems make very little growth in dry summer periods, most evergreen trees do make some root growth in the cooler months.

Certain plant species vary greatly in their ability to tolerate temperature extremes. It is best to use the hardy plants, but 
occasionally some of the more tender species are desired to create a specific landscape effect. Plants known to be on the borderline of hardiness should be placed in protected areas when possible.

Hardiness involves all climatic factors that influence the growth of a plant during its lifespan. Native tree species are usually hardy. Hardiness involves more than the ability of a plant to withstand low temperatures. Rapid temperature fluctuations at any time of the year can be very injurious. A rapid drop in temperature in the fall can kill the twigs, buds, and more importantly, the trunk cambium on species that are slow to harden off.

During the warmer periods of winter, dormant trees may become physiologically active for a short period and then be injured when the temperatures drop to freezing or below. Chinook areas of Alberta are particularly damaging to trees because of the widely fluctuating temperature. Late spring frosts are particularly damaging to those species that break dormancy early. These frosts can kill the new growth and secondary growth must then develop from axillary buds using additional stored food reserves.
Under urban conditions, the intense heat reflected off buildings, sidewalks, and streets can cause prolonged high temperatures not encountered in rural or wooded areas. Prolonged drought periods and drying winds can cause frequent and severe water stress during the summer. Prolonged periods of low temperatures, the amount of soil moisture, and the amount of snow cover are factors that affect the maximum depth that the soil freezes and thus the minimum soil temperatures reached in the root zone during the winter.

Water temperature, nutrient stress and light stress can separately or in combination predispose plants to diseases that ordinarily would not occur. The predisposing concept is especially important in the transplanting of trees and shrubs, since all plants are under stress from the time they are dug and transplanted, through the establishment period. Mechanical and chemical injuries caused by man can cause stress equal to climatic stresses. Many of the future tree problems caused by infectious and noninfectious diseases can be substantially decreased through proper tree selection, planting and after care.
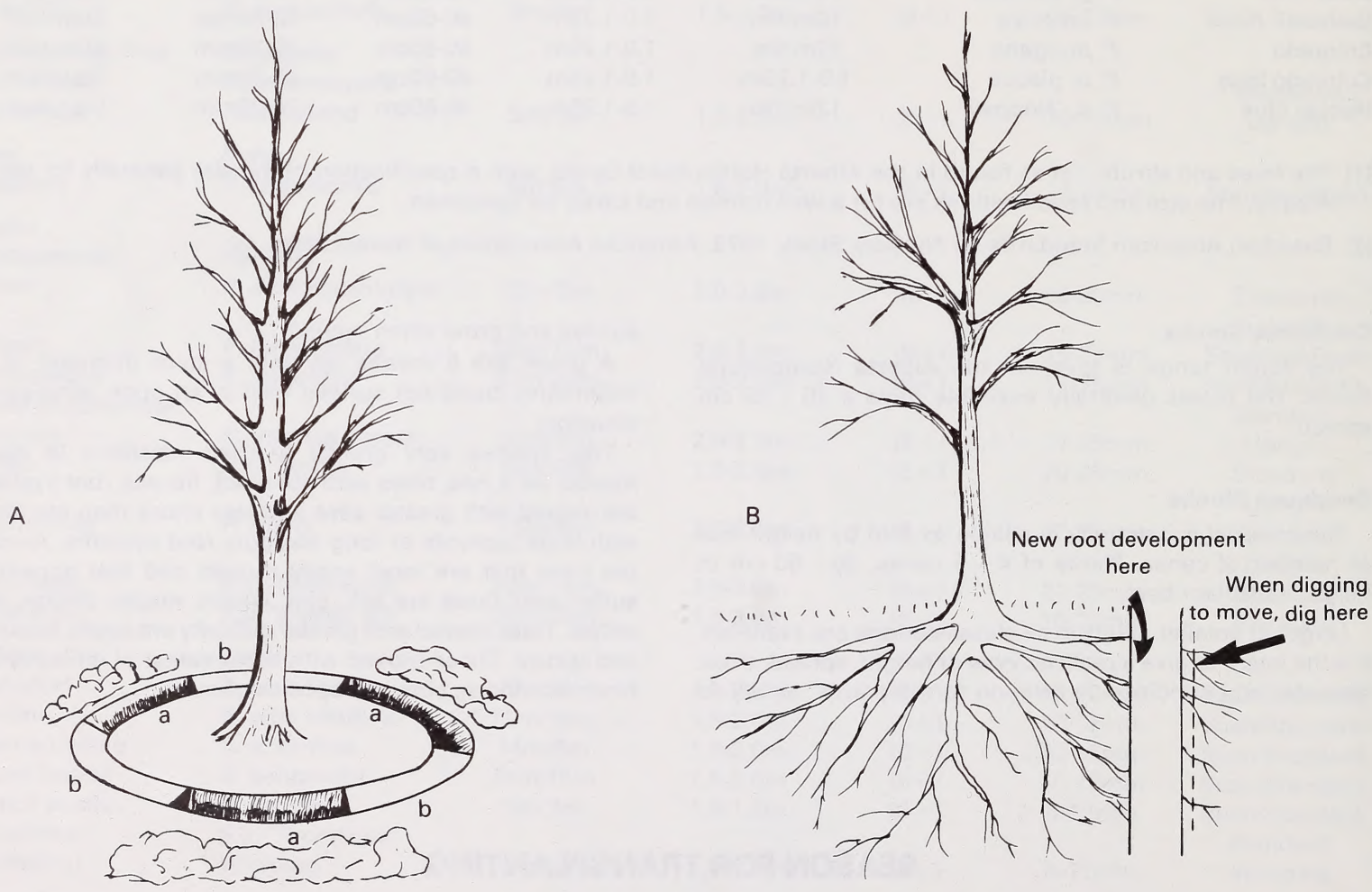

Figure 2. A. Shows where root pruning ought to be done.

B. Shows where to dig to move the tree.

\section{ROOT PRUNING}

Best results are obtained when such trees are root-pruned for two successive years before the actual moving operation. In the spring or fall a circular area around the tree at some distance from the trunk is marked off. The distance varies from tree to tree but is generally $6 \mathrm{~cm}$ distance from the trunk for each $1 \mathrm{~cm}$ diameter measured at 15 to $30 \mathrm{~cm}$ or 1.5 
$\mathrm{m}$ height above the ground depending on the diameter size of the plant and its growth characteristics.

The soil is dug out of areas a, the roots are pruned and the soil is replaced after fertilizer is added. One year later the areas at $b$ are dug and process repeated as for $a$. The tree is ready for moving one year after pruning is done in areas $b$. The diameter of the final digging must be $5-7 \mathrm{~cm}$ greater than the outside diameter of $a$ and b. (Figure 2).
The tree is moved in the third year. The soil placed around the root ball must not be amended but must be the same as dug out. The shock of transplanting is then spread over three years. This principle is very rarely practised. It is presented here to show the optimum method of ensuring greatest success.

\section{PREPARATION FOR PLANTING}

\section{Preparing trees and shrubs for transplanting}

Nursery Grown Trees: Young tree and shrub roots are thin and scraggy and unless such roots are pruned at least one season before digging, transplanting success is very low. Root pruning encourages the roots to branch and to develop a greater abundance of small roots and rootlets with which they take up moisture and nutrients.

Properly managed nursery plants are root pruned every few years, not only to confine the greater part of the root system within a smaller area but to encourage the roots to branch and to develop an abundance of small roots and absorbing tissue. Root pruning will improve transplant efficiency and increase chances for survival.

Wildling (collected) Trees and Shrubs: Naturally growing trees and shrubs have longer and fewer roots than properly maintained nursery stock. Plants growing in medium heavy or clay soils and in open areas are preferable for transplanting to those growing in sandy soil or in heavily wooded areas. Plants growing in protected conditions have shallow roots because of the protection by shade and mulch and are more apt to do poorly when moved to open exposed areas.

As a rule, very small wildling trees are not root-pruned. Large trees on the other hand, can be root-pruned to stimulate the formation of a compact root system and a greater number of fibrous roots.

\section{Soil Preparation}

Soil condition and improvement are important to the success of a replanted tree or shrub. They must be in an optimum condition to provide the plant with the necessities for growth. The particular needs of the plant must be known so that they can be provided. Plants requiring a sandy well-draining texture will do poorly on heavy clay soils while those plants demanding a low pH do poorly on high $\mathrm{pH}$ soils. The soil immediately around the roots should be amended to satisfy the demand. All conditions, soil texture, structure, water holding capacity, nutrient level and $\mathrm{pH}$, must be known of the existing site soil so that the selection of the plants can be done wisely. (See table V pg 28)

Although not advised, when fertilizer is added to the backfill soil, it must be mixed well and a complete type used. Most common soils in Alberta generally have adequate supplies of potassium and most micro-nutrients. The limiting elements are nitrogen and phosphorus. Testing of the site soil should be a common practice before planting. Once identified, fertilizer needs are best placed into Rex-Keyser type holes. (Figure 15).

Most of the functional tree roots are in the top $20-40$ centimetres of soil. Under most conditions this is the level where optimum water and nutrient levels are found.

\section{DIGGING}

Proper digging includes the conservation of as much of the root system as possible, particularly of smaller roots and finer rootlets.

The transplanting operation, regardless of how carefully it is performed, is destructive to a large portion of the absorbing root area. Both the remaining root system and the above-ground plant parts remain in a state of physiological shock. Digging, moving, and planting must be done with the least possible damage to the roots.

Before any digging begins it is advisable to tie in the tree's branches with heavy twine or quarter-inch rope, to reduce the chances of damage or breakage to the branches.

\section{Bare-Root Planting}

Bare-root planting is limited to deciduous shrubs planted in the fall or early spring, and to deciduous trees up to $5 \mathrm{~cm}$ in diameter. Evergreens should always be moved with a soil ball; success is greater than with bare-rooted material.
For larger shrubs over one metre tall, and for trees, a trench is dug around the plant to a depth below the greater part of the root system. To include all other lateral root growth the depth should be $40-50 \mathrm{~cm}$, or deeper for trees.

The trench should be dug just beyond the last rootpruning zone for well-grown nursery trees, or just outside the root-pruning trenches for wildling stock. If no previous root-pruning has been done, as is the case with most trees moved in Alberta today, the trench should be dug at a distance from the trunk allowing 14 centimetres for each centimetre in trunk diameter.

One part of the root system should be uncovered and freed of soil completely before another area is uncovered.

As the roots are uncovered, they must be wrapped in wet burlap to prevent drying and mechanical injury. Wet sphagnum or peat moss should be placed around the roots before being wrapped in burlap if the plants are to be held for several days. Each part of the root system must be 
uncovered and wrapped separately. The tree is then bent over carefully to raise the roots, and the entire root system is tied in a large ball with wet burlap and rope.

Small shrubs may be tied into bundles and heeled-in, or they may be heeled-in separately, to hold them until planting time. Heeling-in should be done in well drained, sandy or sandy-loam soil. Dig a trench as wide and deep as necessary to accommodate the roots. Place the plants in an inclined position in the trench and cover the roots and lower portion of the stems with moist soil. Successive tiers of plants may be added as necessary, but cover each separately. Small evergreens should not be heeled-in because of damage to the closely packed tops. Large shrubs and trees with more spreading roots can be heeled-in in an upright position. The plants should be shaded to keep the tops cool.

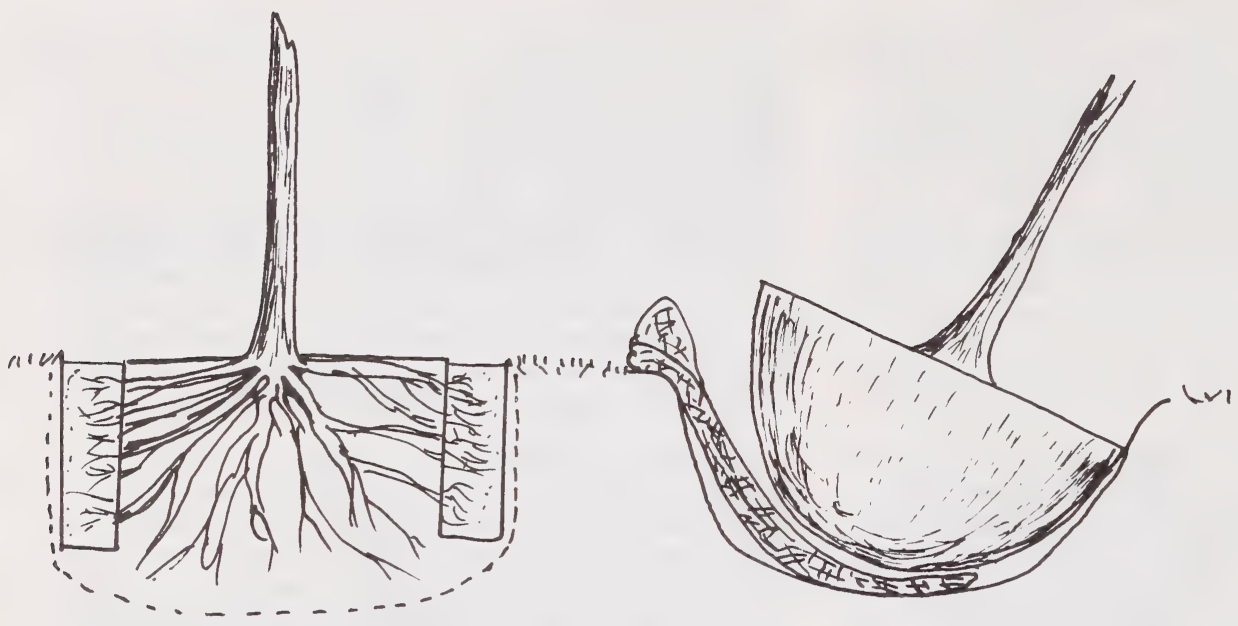

Tilt the plant to cut

Digging Lines bottom roots, and to put burlap under the ball.

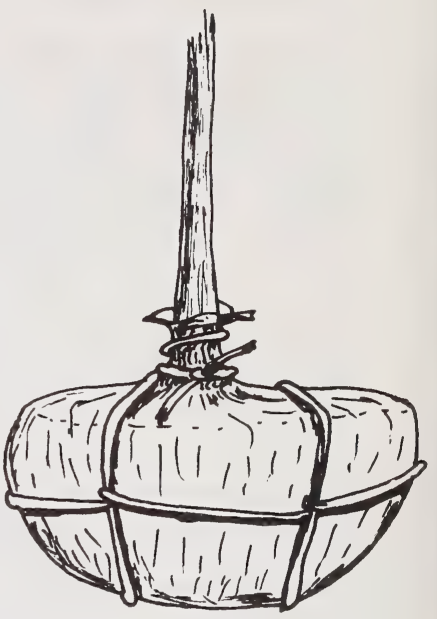

Tie the burlap tightly and securely around ball and trunk.
Figure 3. Digging should be done with a sharp spade. Small shrubs up to 0.9 to 1.2 metres tall do not require the digging of a trench around the plants, except in heavy soils or with species that have a characteristically deep root system. The spade should be inserted into the soil to a depth of 30 centimetres and far enough from the plant to include the majority of fibrous roots. Gently pry away from

\section{Soil Ball}

Evergreens, small deciduous shrubs, small trees in leaf, and whenever possible deciduous trees $8-10 \mathrm{~cm}$ (measured $15 \mathrm{~cm}$ above the ground) and all trees $11 \mathrm{~cm}$ and larger (measured $1.5 \mathrm{~m}$ above the ground), should be moved with a root ball. The objective is the protection of the greatest number of roots in the smallest soil mass. As a rule, trees with a shallow root system require a flat ball, while those with deeply penetrating roots require a deeper ball with a smaller circumference.

The soil ball for deciduous trees is usually 14 centimetres in diameter for each 1 centimetre diameter of the trunk. the plant. Continue cutting around the plant. When the plant has been completely cut around, more prying pressure can be exerted on the spade to break loose the soil beneath the plant to permit the plant to be lifted. Do not attempt to lift the plant until it has been completely cut around. Occasionally the plant must be tilted so that vertical roots can be severed with the sharp spade.
A smaller ball may be used for evergreens. No more soil than is absolutely necessary should remain with the ball, since most soils weigh about $1.8 \mathrm{~g} / \mathrm{cm}^{3}\left(1762 \mathrm{~kg} / \mathrm{m}^{3}\right)$ the ball can become extremely heavy.

To compute the weight of the ball a quick, fairly accurate method is as follows:

[(Diameter of the ball of earth in centimetres $)^{2} \times$ depth of the ball in centimeters $\times 2 / 3 \times 1.8] \div 1000=$ weight in $\mathrm{kg}$ of soil mass. A $45 \mathrm{~cm} \times 35 \mathrm{~cm}$ ball weighs $85 \mathrm{~kg}$.

The soil must be moist before digging. If dry, the soil should be watered thoroughly at least 2 days before digging. If the soil is not moist it will fall away completely. If 


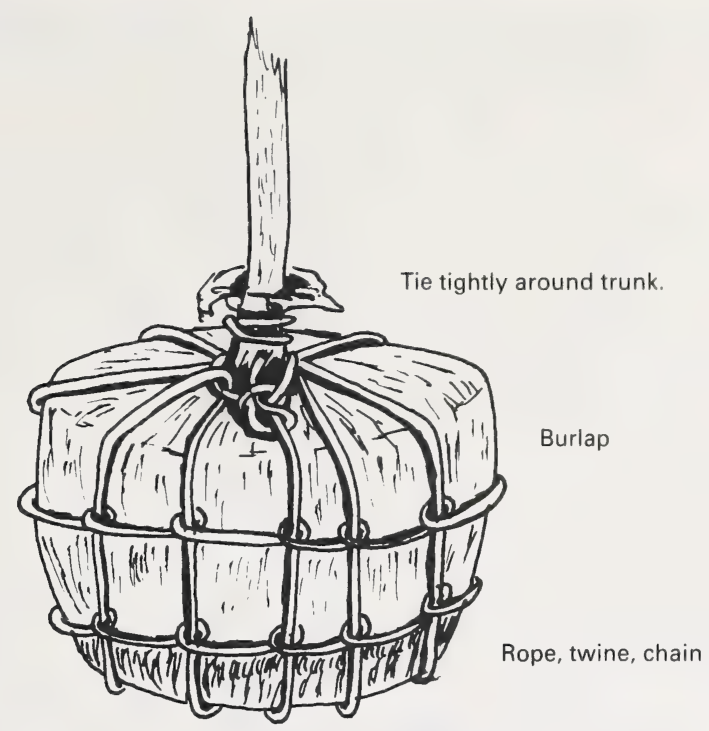

Figure 4. Each crossover is knotted.

considerable time is to elapse before evergreens are to be planted, they must be placed in a shaded area and the soil balls watered frequently.

Plant species that are normally difficult to transplant should have a larger soil ball than those species that are easily moved. The roots of a plant are able to hold together only a limited amount of soil, therefore, it is better to move a plant with a small ball than to take a larger ball and have it break apart.

TABLE 2

\begin{tabular}{rrrc}
$\begin{array}{c}\text { CALIPER OF } \\
\text { TREE IN cm }\end{array}$ & $\begin{array}{r}\text { MINIMUM DIAMETER } \\
\text { OF BALL IN cm }\end{array}$ & $\begin{array}{c}\text { DEPTH OF BALL } \\
\text { IN cm }\end{array}$ \\
\hline $1-2.5$ & 35 & $(35)^{*}$ & 30 \\
$2.5-4.0$ & 40 & $(40)$ & 30 \\
$4.0-5.5$ & 56 & $(48)$ & 34 \\
$5.5-7.0$ & 77 & $(72)$ & 38 \\
$7.0-8.5$ & 98 & $(93)$ & 40 \\
$8.5-10.0$ & 119 & $(114)$ & 58 \\
$10.0-11.5$ & 140 & $(135)$ & 66 \\
$11.5-13.0$ & 161 & $(156)$ & 76 \\
$13.0-14.5$ & 182 & $(177)$ & 79 \\
$14.5-16.0$ & 203 & $(198)$ & 84 \\
$16.0-17.5$ & 224 & $(218)$ & 88 \\
\hline
\end{tabular}

* For coniferous or evergreen trees the diameters are somewhat less, (shown in parentheses above). The ball depth should not vary.

For sizes beyond the chart multiply caliper $x 14$.

e.g., a $20 \mathrm{~cm}$ tree requires a $280 \mathrm{~cm}$ ball.

When the ball of earth is wrapped in burlap, using one continuous piece and securely tied, it is referred to as a B \& B tree or shrub.

The box method is commonly used to move a tree or large shrub from a sandy soil. Once a square trench is made around the tree, four pieces of board are nailed to form the sides of a box the same size as the square left around the tree. The soil under the root system is dug out and additional boards are slid under and fastened in place to complete the box. 
The depth of the ball will correspond to the depth in Table 2 with the minimum $35 \mathrm{~cm}$ being used for the smallest calipers, eg., the $45 \mathrm{~cm}$ diameter requires minimum $30 \mathrm{~cm}$ depth, $70 \mathrm{~cm}$ diameter minimum $38 \mathrm{~cm}$ depth.

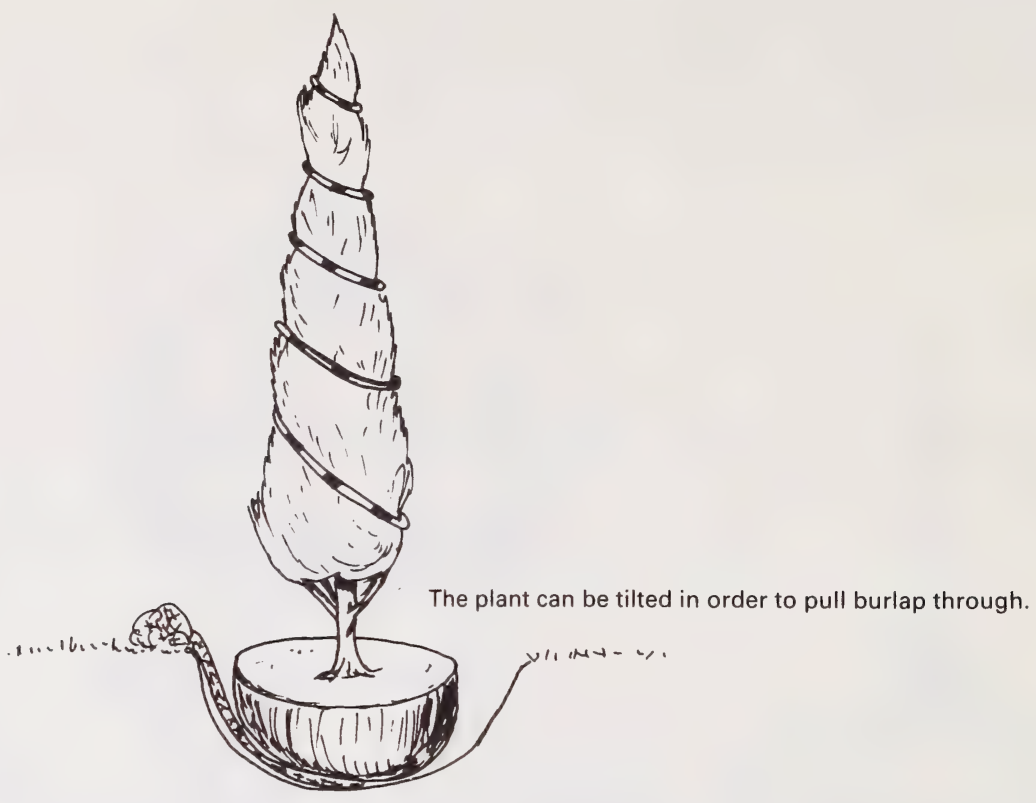

Figure 5. Typical digging and balling operation

Tie in branches, dig, and trim the soil ball of the evergreen tree. Branches are tied with rope, cord, or strips of burlap. The trench is dug approximately $3 / 4$ of the desired depth of the finished ball and is then undercut and trimmed. The burlap is fed under the completed ball and sufficiently pulled through to cover the entire ball.
Rope or twine is pulled tightly around the ball starting at the trunk.

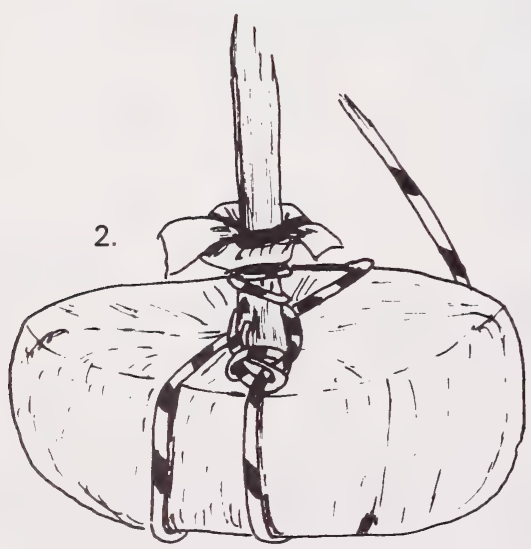

Figure 6. Burlapping small soil balls. These illustrations show successive steps in burlapping and roping small balls. Be sure

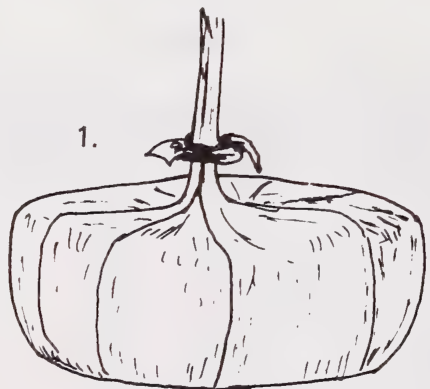

The burlap is wrapped securely around the trunk to protect the bark.
Rope or twine is tied tightly to trunk and around top of ball.

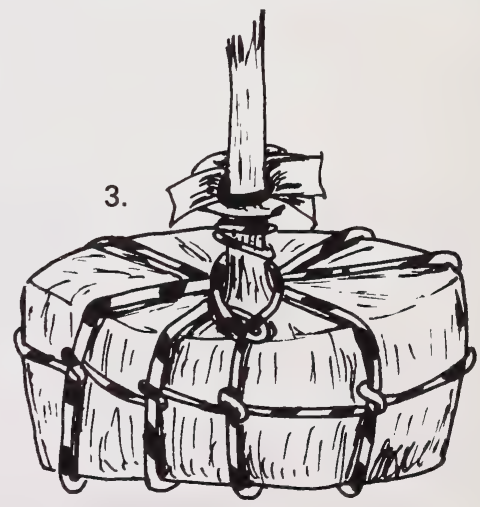




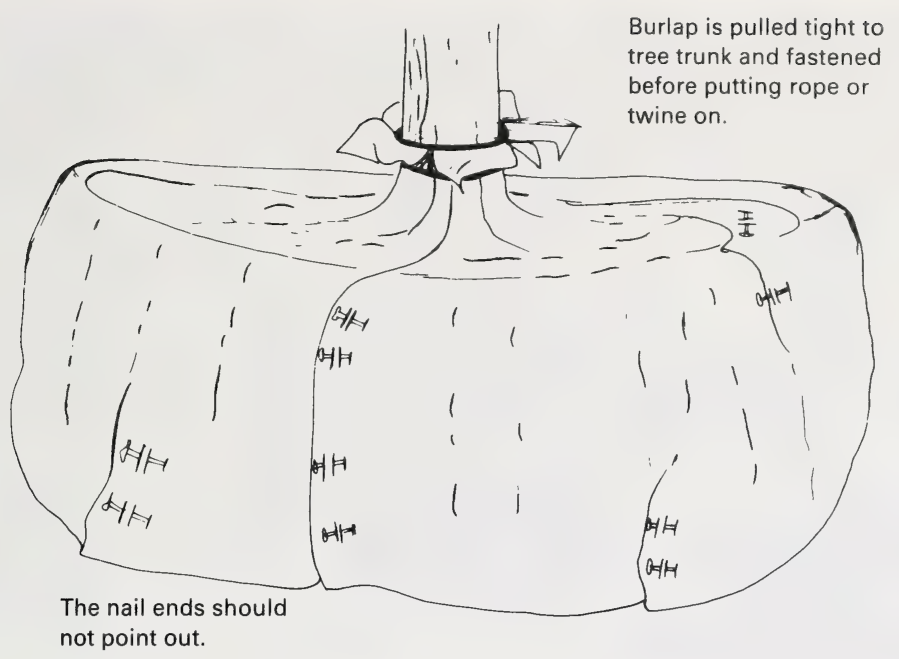

Figure 7. Burlapping large soil balls. The burlap is laid so that it extends over the top of the ball about $30 \mathrm{~cm}$. It is pulled tight and held in place with nails. Square pieces of burlap may be substituted

\section{Tying Very Large Tree Balls}

The method is simple and quick as it is not necessary to pull the entire length of lacing rope beneath the top and bottom ropes at each turn in the threading process. The top loop of rope should be $30 \mathrm{~cm}$ in diameter smaller than the ball diameter. Place the loop around the top of the ball, 15 $\mathrm{cm}$ from the edge. Tie the ends tightly in a square knot. Hold the rope in place with staples, or wire pins. Wire pins made from \#9 wire with a loop on top are easier to push in and

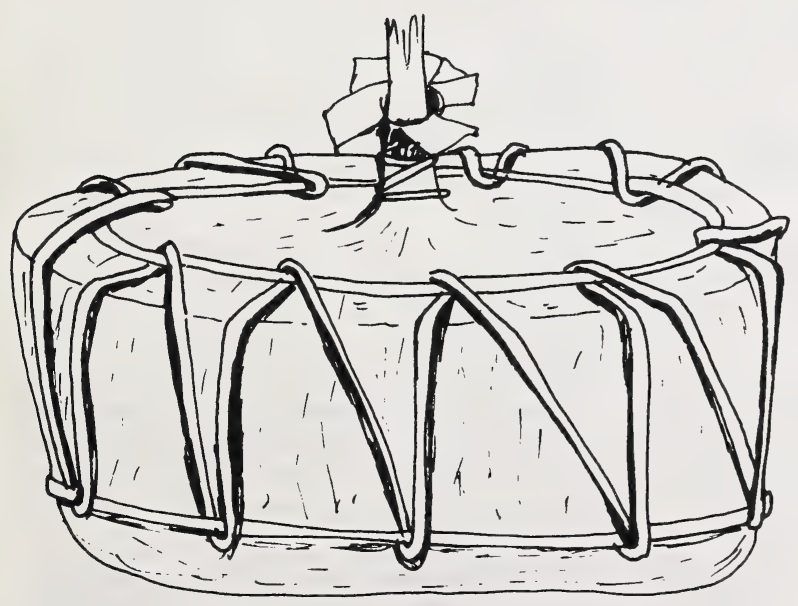

Figure 8. Open-link method of roping. In some soils, the ball may be tapered more at the bottom to lessen soil weight. The bottom of the for long pieces by pinning the pieces together with nails. After the ball is removed from the hole, it is a good practice to pin the burlap together across the bottom of the ball.

remove than are nails or staples. Lay the bottom rope close to the bottom of the burlap and tie the ends together with bowline knot on one end, and two half-hitches on the other. Insert the open links in the top and bottom ropes at equal distances around the ball. The bottom ones should be interspersed with the top ones. The distance between the links should be 15 to $46 \mathrm{~cm}$, depending upon the size of the ball and the type of soil. They should be placed at closer intervals for sandy and loose soil.

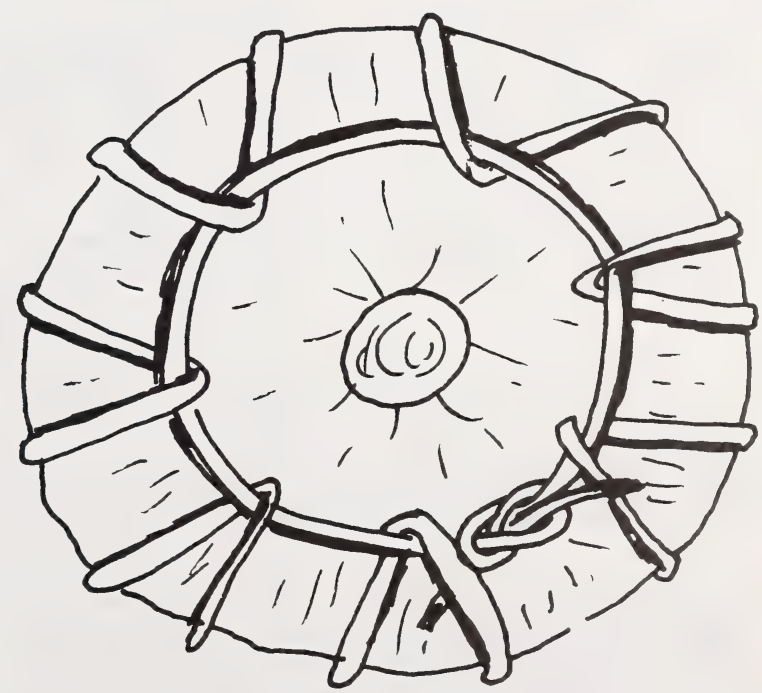

burlap is later pinned together. A top view of the open-link method is shown in Figure 10. 


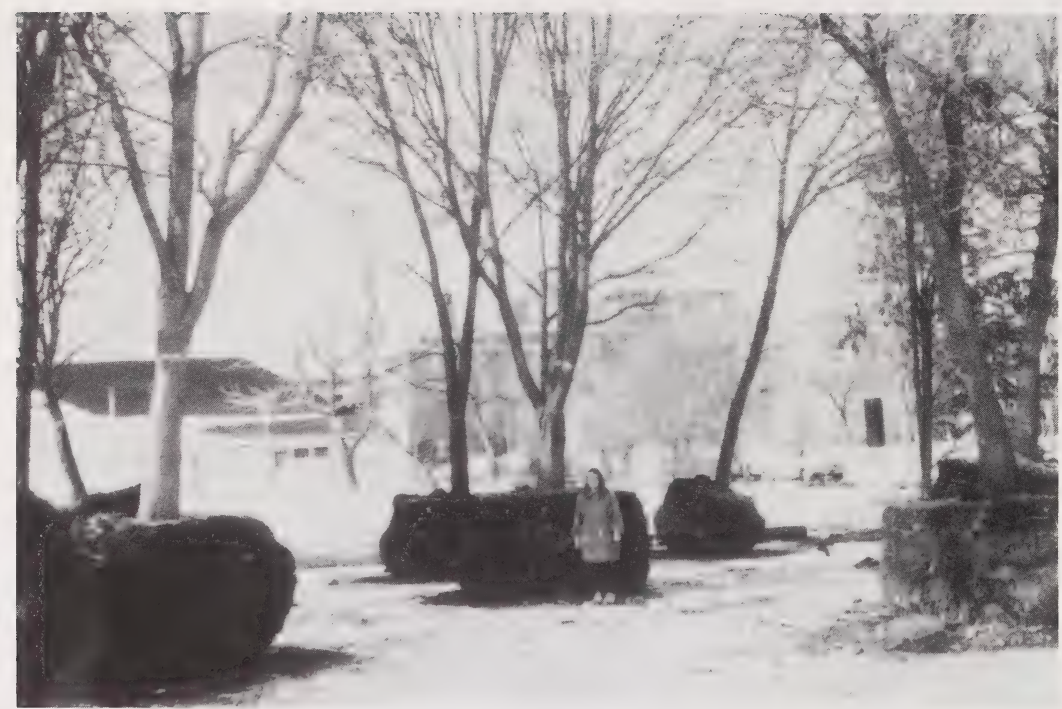

Figure 9. Very large trees are dug out by backhoe and crane in a frozen state to ensure a large stable root mass. This type of transplanting requires much care and knowledge. Although expensive, if properly done it is very successful.

Except in sandy loose soil, top lacing is not necessary for soil balls up to $1.2 \mathrm{~m}$ in diameter. If top lacing is required, run the rope back and forth across the top to form a triangle. A $6 \mathrm{~mm}$ rope is sufficient. Continue to weave the top of the ball until there is cross rope at each space between the open links or loops of the drum weaving. Secure it tightly to the top rope. Top lacing can be done using the open links or by looping the rope under and over the top drum-lace rope.

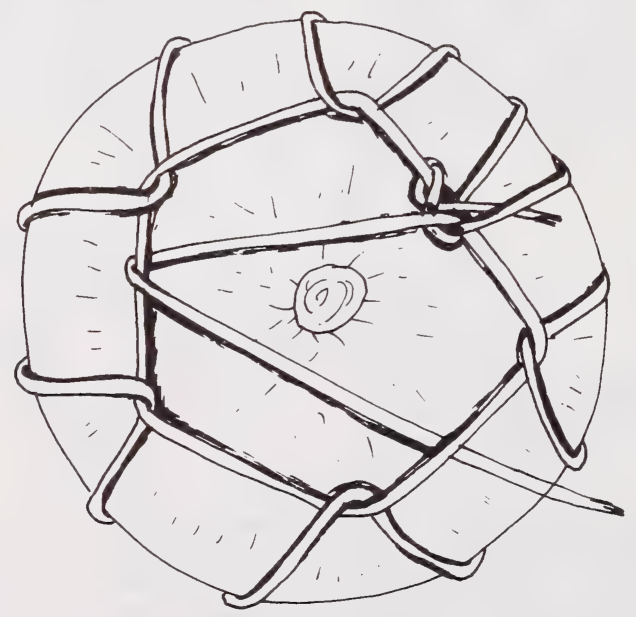

Figure 10. Top Lacing. Top view of a soil ball where the weave-rope method was used. Top lacing is accomplished by runnirg the rope across the top of the ball in triangular fashion. Continue lacing until

DIGGING Remove the sod or loose soil from around the plant, being careful not to injure or cut surface roots. Mark a circle 15 to $20 \mathrm{~cm}$ beyond the diameter of the finished ball. This will allow for final trimming and shaping of the ball. With the back of the spade facing the plant, cut straight down $20-30 \mathrm{~cm}$, severing all roots. Repeat around the there is a cross rope at each space between the open loops of the drum weaving. The bottom of the ball should also be laced if the soil is sandy or loose.

entire circle. Dig a trench beyond the circle to a depth of $25-30 \mathrm{~cm}$, or approximately three-fourths of the desired ball depth. Do not undercut the ball until after shaping is completed. Always work with the back of the spade toward the ball to prevent prying up the root prematurely. 


\section{TABLE 3 - PLANT HEIGHTS AND MINIMUM DIAMETER OF BALL TO BE USED \\ DECIDUOUS SHRUBS \\ SMALL TREES \\ CONIFEROUS/EVERGREEN TREES \\ CONIFEROUS/EVERGREEN SHRUBS}

Height

Minimum diameter

Height

Minimum diameter

of ball $(\mathrm{cm})$

Mininum diameter of ball $(\mathrm{cm})$

\begin{tabular}{|c|c|c|c|c|c|c|}
\hline 45 & -60 & $\mathrm{~cm}$ & 25 & 45 & -60 & $\mathrm{~cm}$ \\
\hline 0.5 & -1.0 & $\mathrm{~m}$ & 30 & 0.5 & -1.0 & $\mathrm{~m}$ \\
\hline 1.0 & -1.5 & $\mathrm{~m}$ & 35 & 1.0 & - 1.5 & $\mathrm{~m}$ \\
\hline 1.5 & - 1.75 & $m$ & 40 & 1.5 & - $\quad 1.75$ & $5 \mathrm{~m}$ \\
\hline 1.75 & -2.0 & $\mathrm{~m}$ & 45 & 1.75 & -2.0 & $\mathrm{~m}$ \\
\hline 2.0 & $-\quad 2.25$ & $m$ & 50 & 2.0 & 2.25 & $5 \mathrm{~m}$ \\
\hline 2.25 & -2.5 & $\mathrm{~m}$ & 60 & 2.25 & -2.5 & $\mathrm{~m}$ \\
\hline 2.5 & - 2.75 & $m$ & 70 & 2.5 & $-\quad 2.75$ & $5 \mathrm{~m}$ \\
\hline 2.75 & - $\quad 3.0$ & $\mathrm{~m}$ & 80 & 2.75 & - $\quad 3.0$ & $\mathrm{~m}$ \\
\hline 3.0 & $-\quad 3.5$ & $m$ & 90 & 3.0 & $-\quad 3.5$ & m \\
\hline 3.5 & -4.0 & $\mathrm{~m}$ & 100 & 3.5 & -4.0 & m \\
\hline 4.0 & - 4.5 & $\mathrm{~m}$ & 110 & 4.0 & -4.5 & $\mathrm{~m}$ \\
\hline 4.5 & $-\quad 5.0$ & $\mathrm{~m}$ & 120 & 4.5 & $-\quad 5.0$ & $\mathrm{~m}$ \\
\hline & & & & 5.0 & $-\quad 5.5$ & \\
\hline
\end{tabular}

Round off the top of the ball to prevent breaking or crumbling while wrapping with burlap. Starting about 15 $\mathrm{cm}$ below the top and extending to the base, the ball should be tapered to its final shape. The diameter of the ball at its base should be 15 to $30 \mathrm{~cm}$ less than the diameter of the top.

Once the burlap is fitted into place and secured as described, the plant can be undercut and made free.

Soil balls up to $90 \mathrm{~cm}$ in diameter can be broken free by undercutting one side and tipping the ball over. If necessary, a rope can be placed around the top of the ball and pulled over using a pry-pole. After tipping, trim off the excess soil from the bottom and cut projecting roots.

Under most soil conditions, direct lifting of large balls will fracture the bottom of the ball if all bottom roots are not severed. Soil balls may be undercut by running a small steel cable around the bottom of the ball below the burlap and securing both ends to a hook in the end of another cable running to a winch. When power is applied, the cable cuts cleanly underneath the ball, severing all small roots. Care must be taken to keep the pulling ends of the cable as low as possible in the hole to obtain a level cut across the bottom of the soil ball. Two heavy steel pry bars can be used to hold the cable down.

When large roots are encountered, undercutting can be done by placing a choker cable at the base of the ball and working the cable through the soil with the aid of an articulated machine such as a Michigan Loader. Or, anchor one end of a cable securely to a steel bar anchored at the bottom of the hole. Loop the base of the ball with the cable and pass it through a slit trench to a power winch. When power is applied to the cable the cable loop applies even pressure as it cuts through the base of the ball.

All safety precautions must be followed when removing the plant. Never underestimate the weight of the ball. If it is not to be moved immediately leave the plant in the hole and cover with moist moss or leaf mold, etc. A front-end loader or a crane may be necessary to move the plant. The use of cradle chains or ball slings to lift the plant is then recommended.

$\begin{array}{lllll}36 & 45 & -60 & \mathrm{~cm} & 36 \\ 38 & 0.5-1.0 & \mathrm{~m} & 40 \\ 40 & 1.0-1.5 \mathrm{~m} & 50 \\ 43 & 1.5-1.75 \mathrm{~m} & 65 \\ 46 & 1.75-2.0 \mathrm{~m} & 80 \\ 50 & 2.0-2.25 \mathrm{~m} & 95 \\ 60 & 2.25-2.5 \mathrm{~m} & 110\end{array}$

70

80

90

100

110

120

135

150

The tree trunk should be well padded where the cable is attached to it, to avoid strain on the trunk as much as possible. Avoid breaking of branches when pulling the tree over and out of the hole, the branches should be tied-in as soon as the tree is pulled over. The inside curve of bent branches is subject to buckling of the bark; on the outside curve of branches, the bark can easily stretch or crack and cause death of the branch; do not bend large branches so severely that the bark slips.

When moving very large trees requiring a ball of $1 \mathrm{~m}$ or more, chicken wire should be used over the burlap to hold the soil ball intact. Using the proper rope size is imperative. For ball diameters up to $1.5 \mathrm{~m}$ use 13 or $16 \mathrm{~mm}$ rope for the top and bottom ties and $6-13 \mathrm{~mm}$ ropes for lacing. When over $1.5 \mathrm{~m}$ use $16-25 \mathrm{~mm}$ rope for ties and $13-16 \mathrm{~mm}$ rope for lacing.

Some recommend the use of pins driven through the trunk when moving very large trees out of the hole. It is our recommendation that pins not be used for fear of splitting the trunk and causing severe internal problems.

Unless the tree can be planted it should not be moved from the hole. If it must be moved and stored above ground all precautions must be taken to ensure it will not dry out nor tip over if left upright. The ball MUST be kept moist and shaded at all times.

\section{Transplanting Container-Grown Trees and Shrubs}

Container-grown plants extend the planting season, the plants suffer from less shock on transplanting, few if any roots are lost, and the plants need not be planted immediately.

Metal, plastic or other impervious containers must be removed before planting, fibrous ones need only be slashed and those such as jiffy pots need not be removed. Potted plants should have the root ball broken or loosened to some extent, to expand the roots and loosen them. If this is not done, the tree or shrub may continue to grow in the pot media for a considerable length of time and this may result in girdled roots later on. 


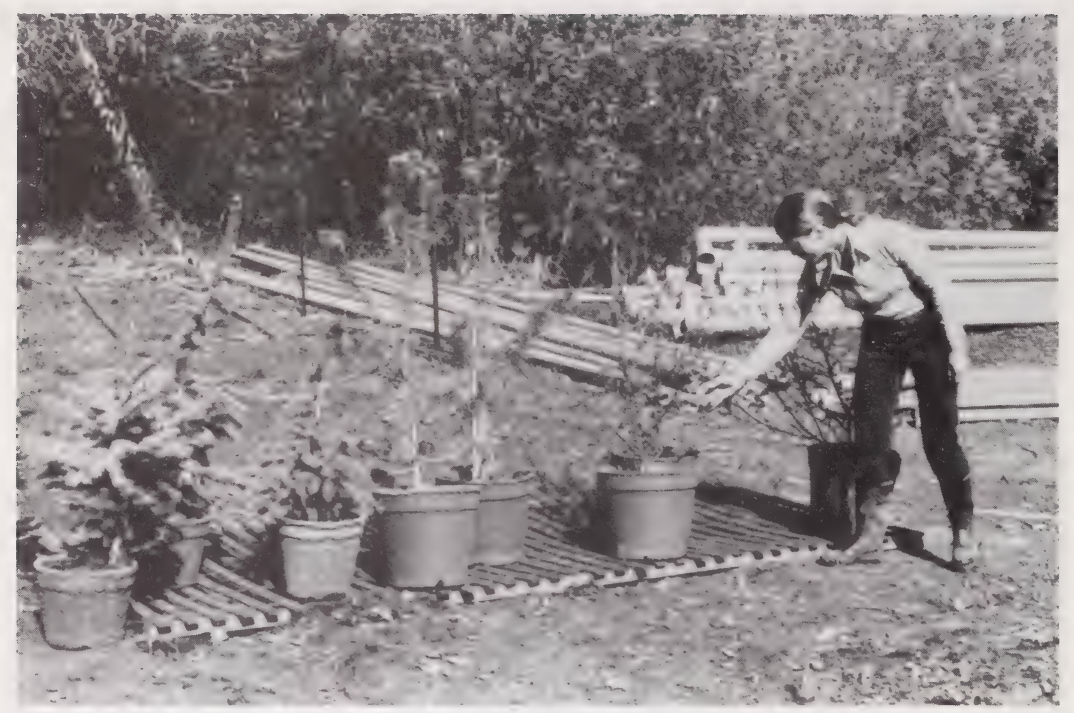

Figure 11. Container stock planting is gaining in popularity. By this method plants can be planted in almost any season.

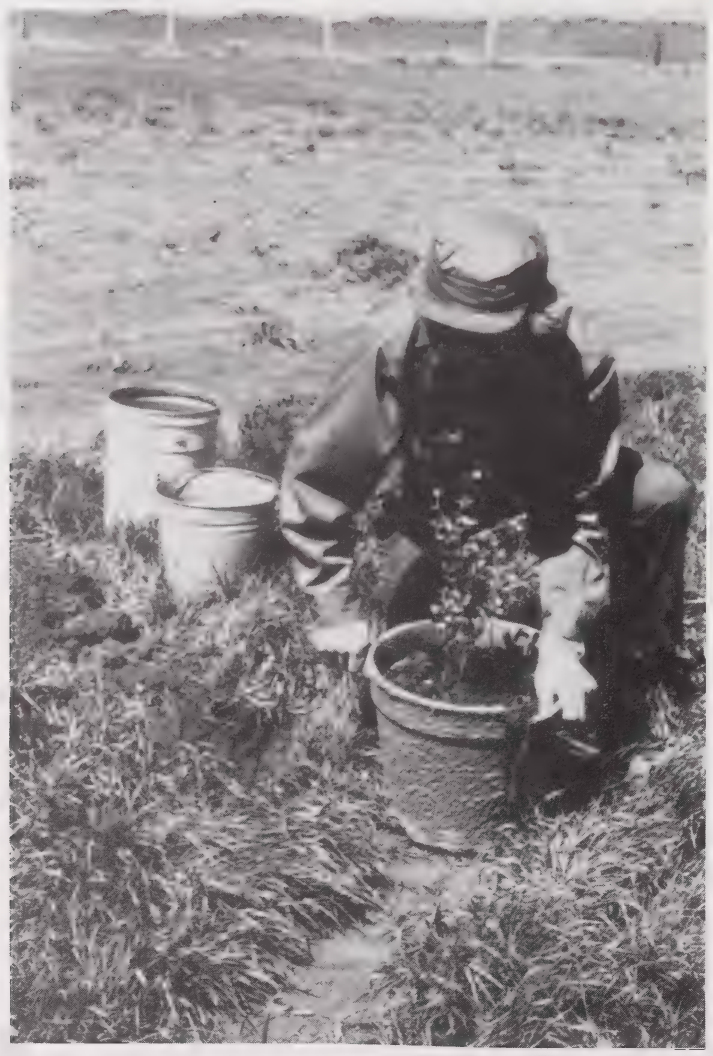

Figure 12. It is advisable to cut the pots to ensure the escape of roots in cold soils. 


\section{TRANSPORTING}

Small trees and shrubs are easily moved. Large plants require special equipment. Large tree moving machines such as cranes, trailers and sleds are available.

The only limits now imposed on moving large trees are the amount of road clearance required, the weight roads and bridges will stand and the number of people available (generally $3-7$ people are required to move trees from $20-60 \mathrm{~cm}$ in diameter.)

The following precautions are necessary to prevent injury to large trees:

1. Pad unprotected areas (branch, trunk) with burlap, canvas, etc. to avoid bruising and slipping of the bark.
2. Tie all loose ends with soft rope or twine to avoid twig and branch breakage.

3. Keep the earth ball moist or cover exposed bare roots with wet burlap or moss.

4. Avoid excessive drying of the tops, especially evergreens, while in transit. Cover them with wet burlap or spray with anti-transpirants. (Such as Wilt-Pruf, ${ }^{\top M}{ }^{\mathrm{M}}$ Foli-gard, $^{{ }^{\mathrm{T}} \mathrm{M}}$ etc.)

5. Cover bare rooted trees and shrubs being transferred in open wagons or trucks.

6. Never use excessive speed on highways, especially with uncovered trees.

\section{PLANTING}

\section{The Site}

Great care must be taken in the preparation of the new site. The hole must be dug large enough to accommodate the full root system. In especially poor soils it should be larger and deeper to accommodate new, fertile soil. As the hole is dug, the top soil should be separated from the subsoil.

Plants placed in heavy or poorly drained soils will perish if precautions are not taken to improve the drainage prior to planting. Fracturing the subsoil by any means improves the drainage.

Bare-root plants should be placed in a hole both wide enough and deep enough to accommodate the entire root system. The roots should be straightened to prevent doubling-under, crowding, and crossing. Roots which may later girdle other roots or the trunk should be cut off with sharp pruners.

Balled plants should be placed in a hole at least $30 \mathrm{~cm}$ wider than the soil ball. This will allow space for backfill to be worked down and around the ball to avoid air pockets. Plants with soil balls larger than $100 \mathrm{~cm}$ should have 45 to $60 \mathrm{~cm}$ of space around them.

Plants should not be planted deeper than they were in their former location. An allowance should be made for settling when bare-root plants are used. When balled plants are used, the top of the ball should be flush with the top of the hole or 2 to $5 \mathrm{~cm}$ above if the soil at the site is poorly drained.

\section{Setting the Tree}

The depth of planting must be as close as possible to the original, as measured from the soil stain on the trunk. Lifting the tree slightly above the soil stain ring may improve success. Never plant deeper than the original depth.

The new soil must not be too wet or too dry. Moist conditions must prevail.

Never place the plant in the hole until the depth has been adjusted and the soil is in the proper moist state. This is especially true of large trees.

A cone-shaped mound of soil at the bottom of the hole is advised for bare-root plants. The root crown of bare-root plants is set on the mound and the roots spread over and down the sides thus assuring close contact with the soil. The soil is added gradually working it in firmly around the roots. Large air spaces must be avoided. The tree may be gently raised and lowered during the filling process to eliminate air pockets and bring the roots in close contact with the soil. Water may be added to eliminate air pockets. When the roots are covered, tamp the entire area firmly. Heavy soils should not be tamped too firmly; otherwise oxygen and water will not penetrate through to the roots.

Balled trees and shrubs are handled somewhat differently. The rope holding the burlap in place is removed and the burlap loosened; the burlap will soon rot away. Soil is added to half fill the empty space and tamped firmly, water is then added to dispel any air and to settle the soil; when the water has drained the remainder of the soil is put into the hole.

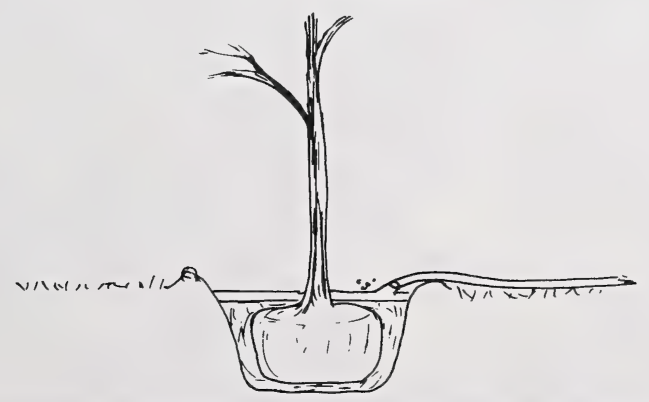

Figure 13. The soil level around the tree should be a few inches below the level of the surrounding ground. This is to form a basin to hold water. The ridge around the basin should be levelled before winter to prevent water from freezing around the trunk and injuring it. 


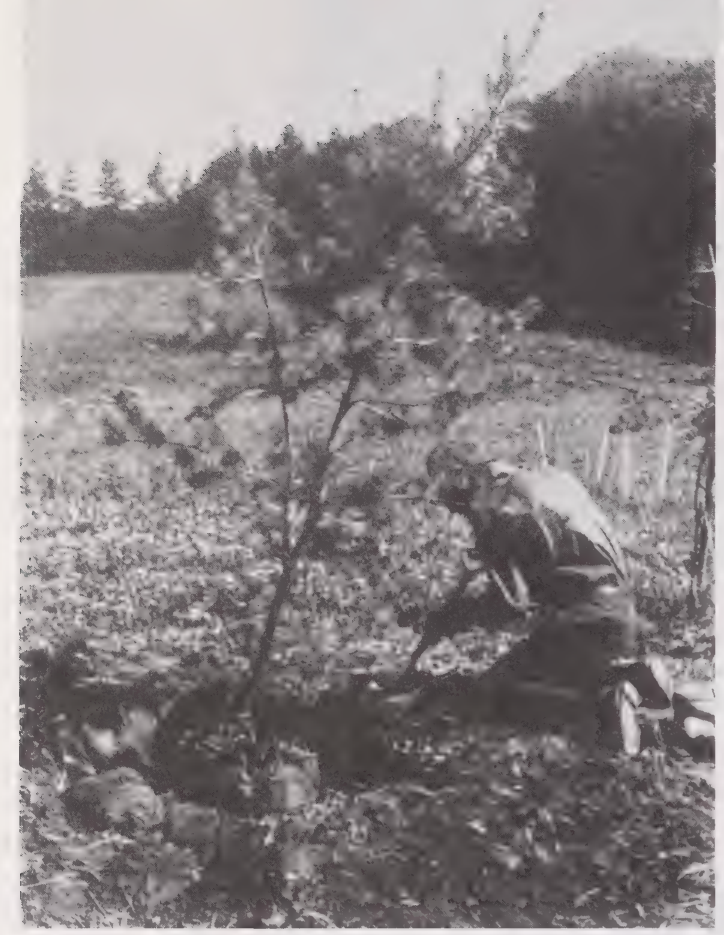

Figure 14. Digging

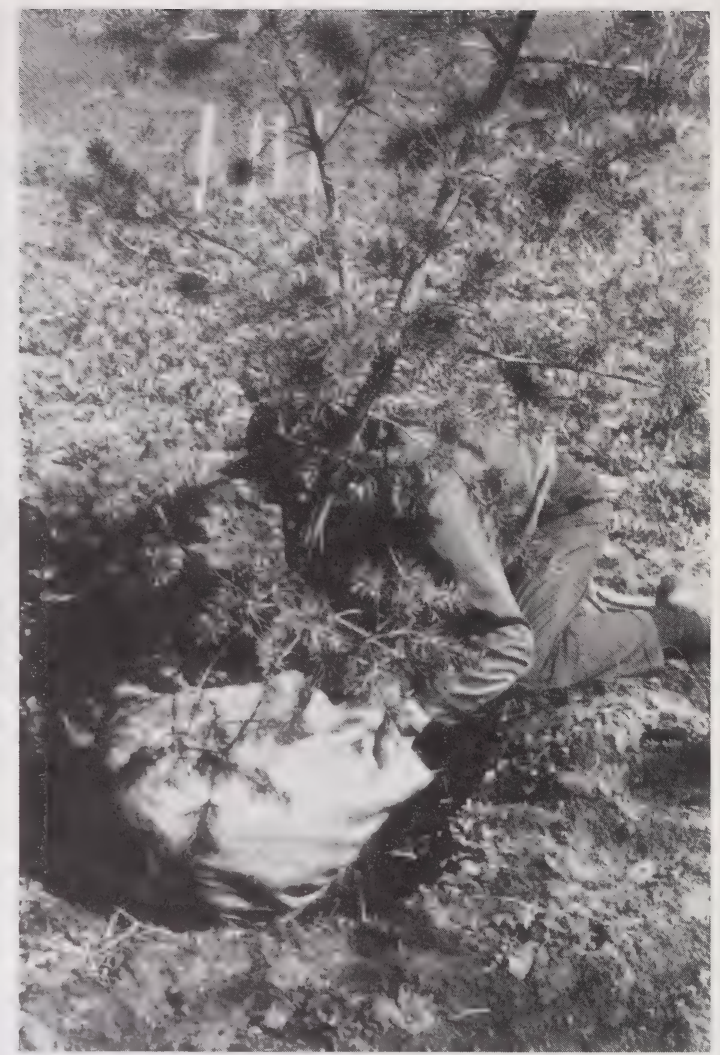

Figure 15. Burlapping

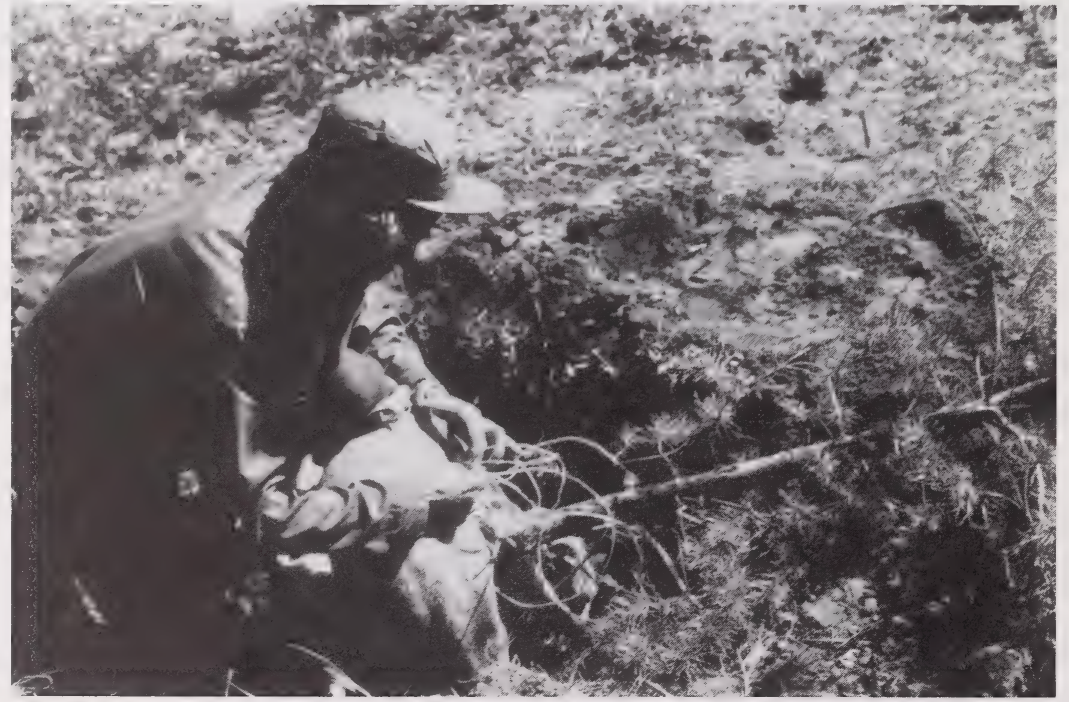

Figure 16. Tying 


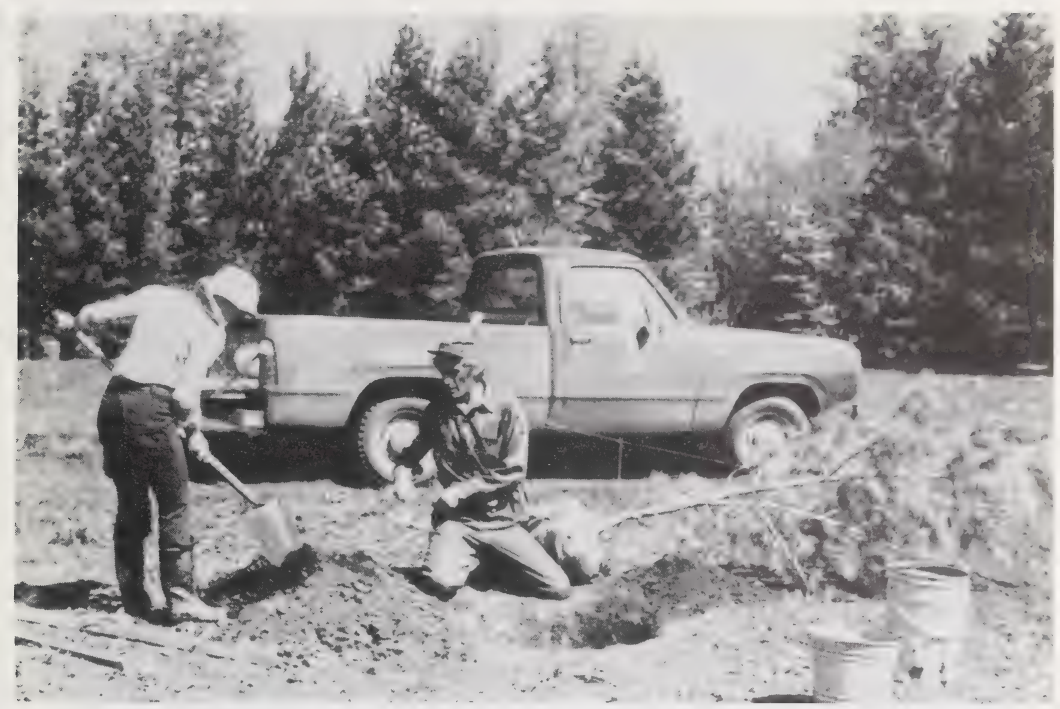

Figure 17. Digging new hole separating the soil

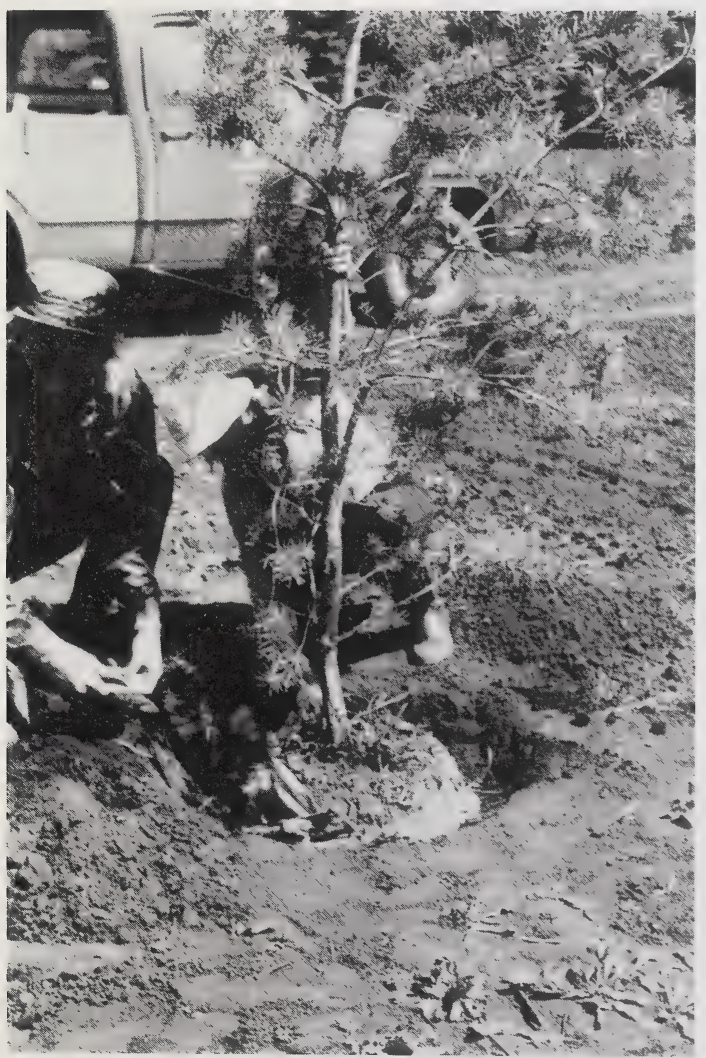

Figure 18. Removing the burlap

- leave burlap in hole

- remove plastic twine if used

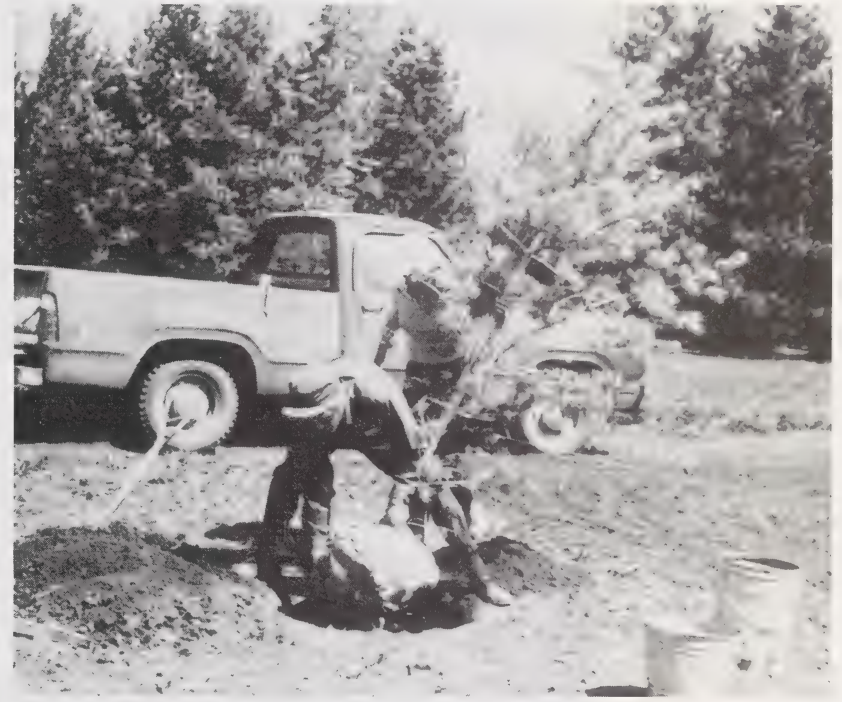

Figure 19. Setting tree in the hole 


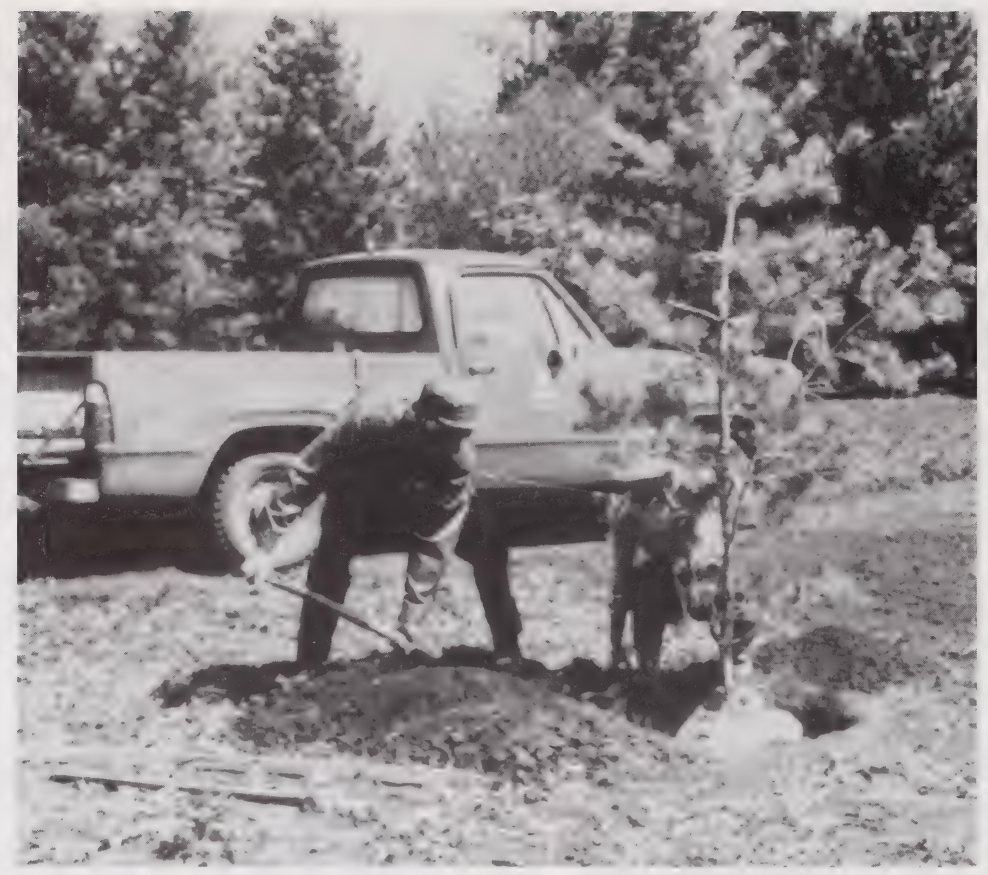

Figure 20. Replacing the soil

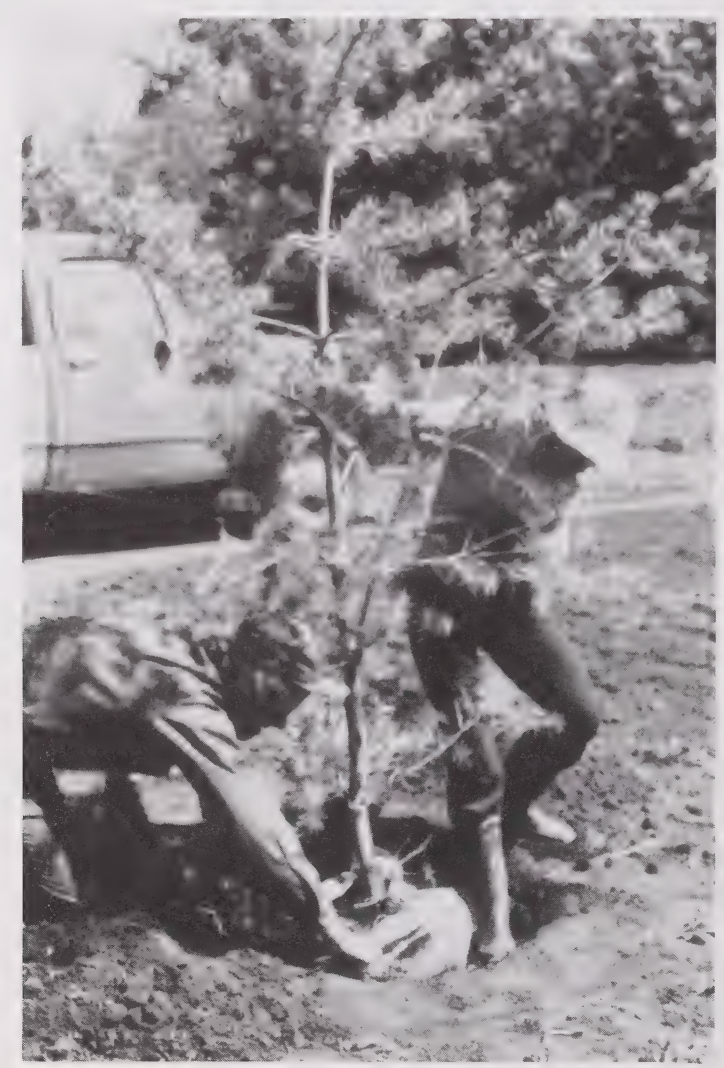

Figure 21. Pressing in soil 


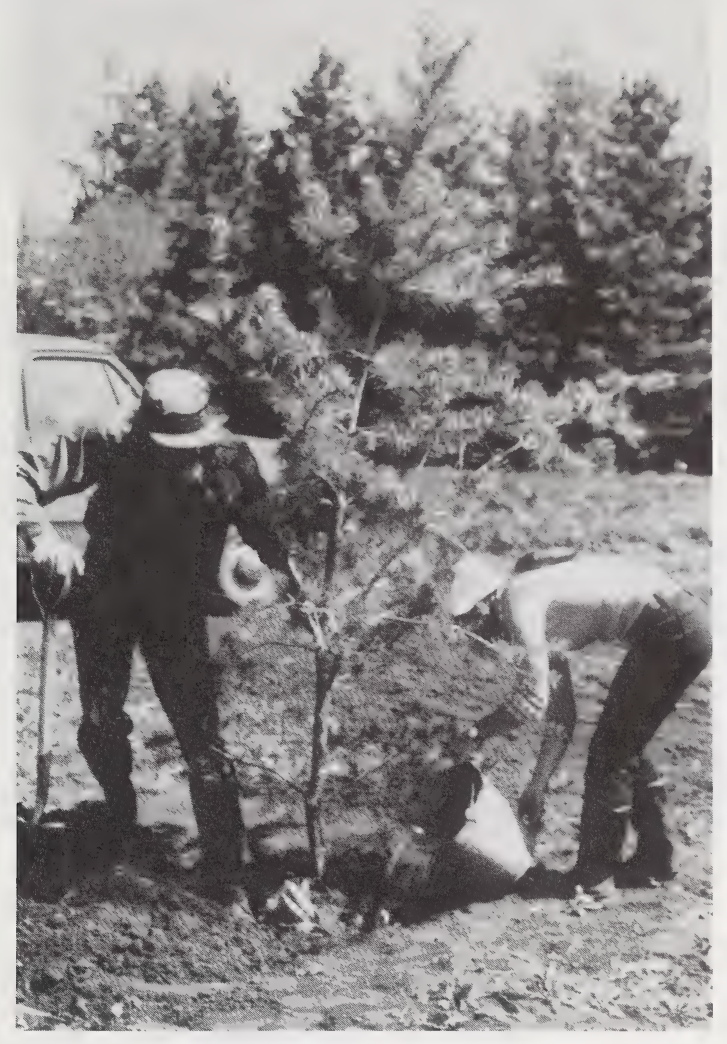

Figure 22. Watering in first layer of soil

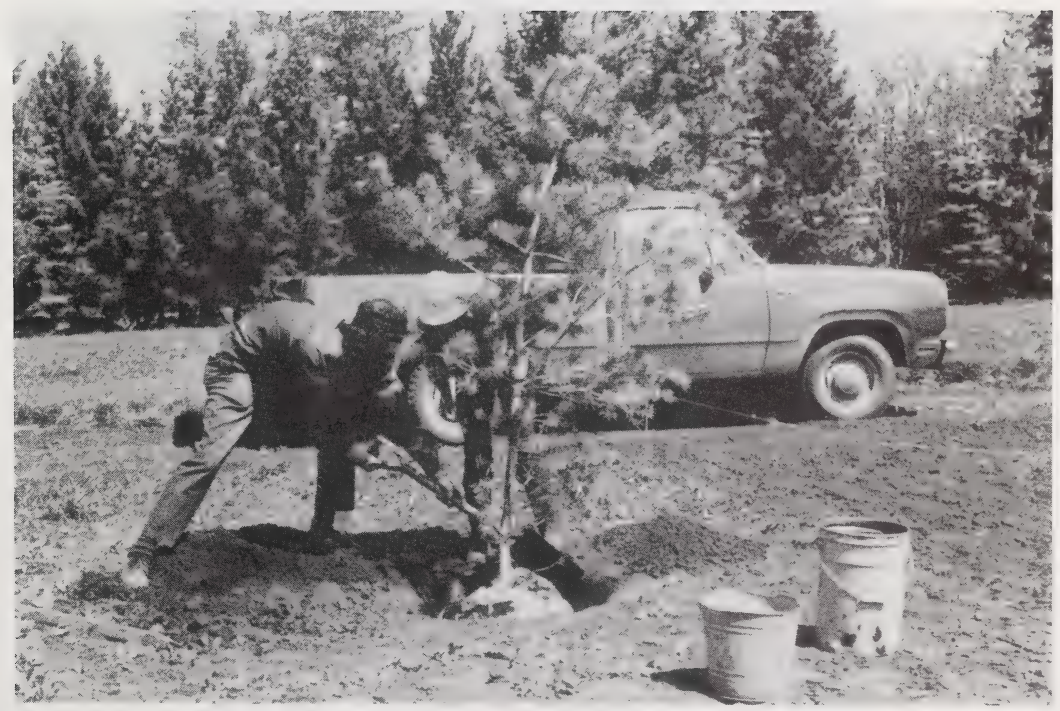

Figure 23. Complete by replacing the soil 


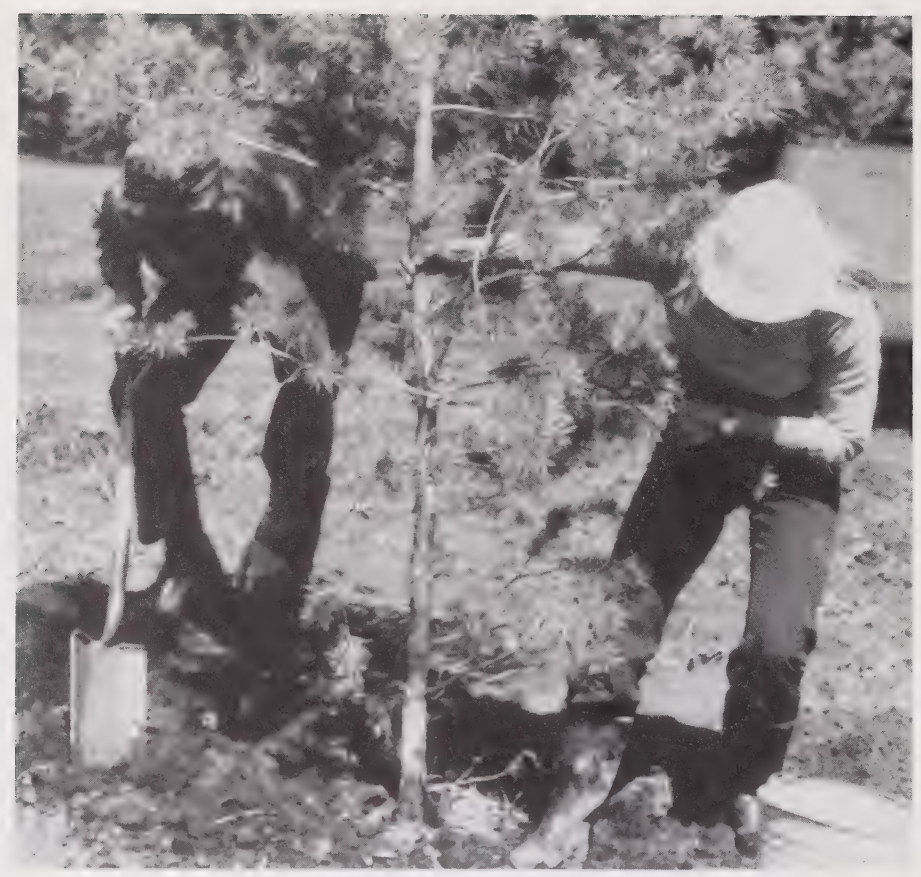

Figure 24. Firming in last layer of soil

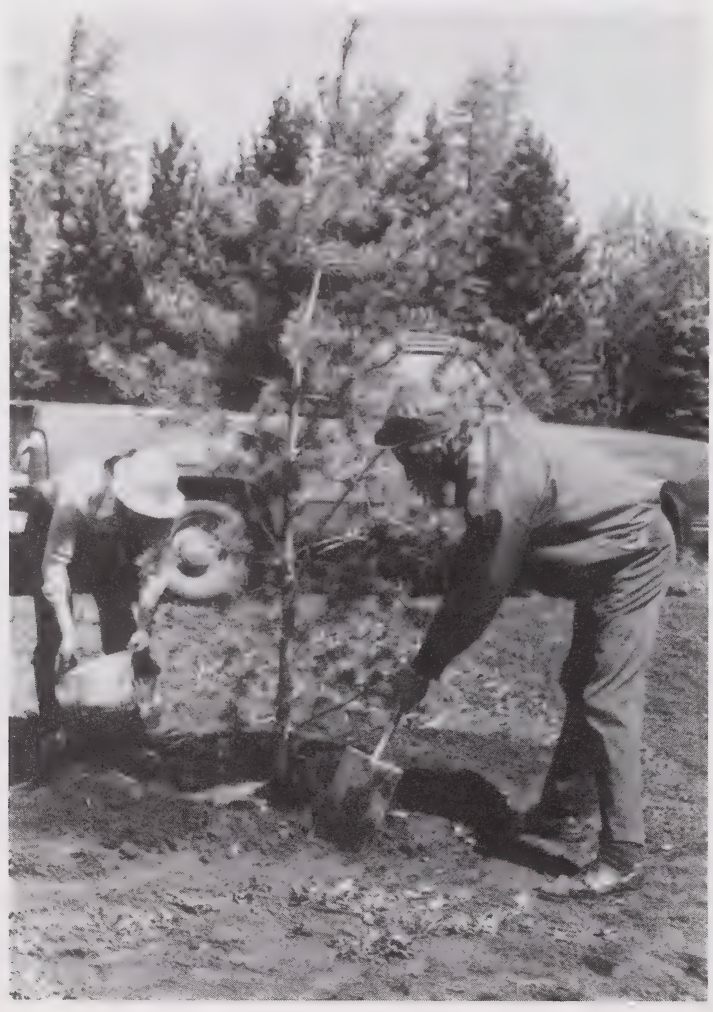

Figure 25. Making the water holding dish and final watering 
Plants dug several days previously and not properly cared for may arrive at the planting site with the outer inch or so of soil dried out. Also, the ball surface may be glazed when dug from wet soil. After digging and before burlapping, the glazed surface should be scarified with a shovel. A crusted soil surface inhibits the movement of air and water to the roots and the new roots will penetrate the crust with difficulty. When planting a crusted ball, it is best to cut or slit the surface to permit a better amalgamation of the ball surface with the backfill soil. Always avoid injuring roots and do not break up the ball of soil.

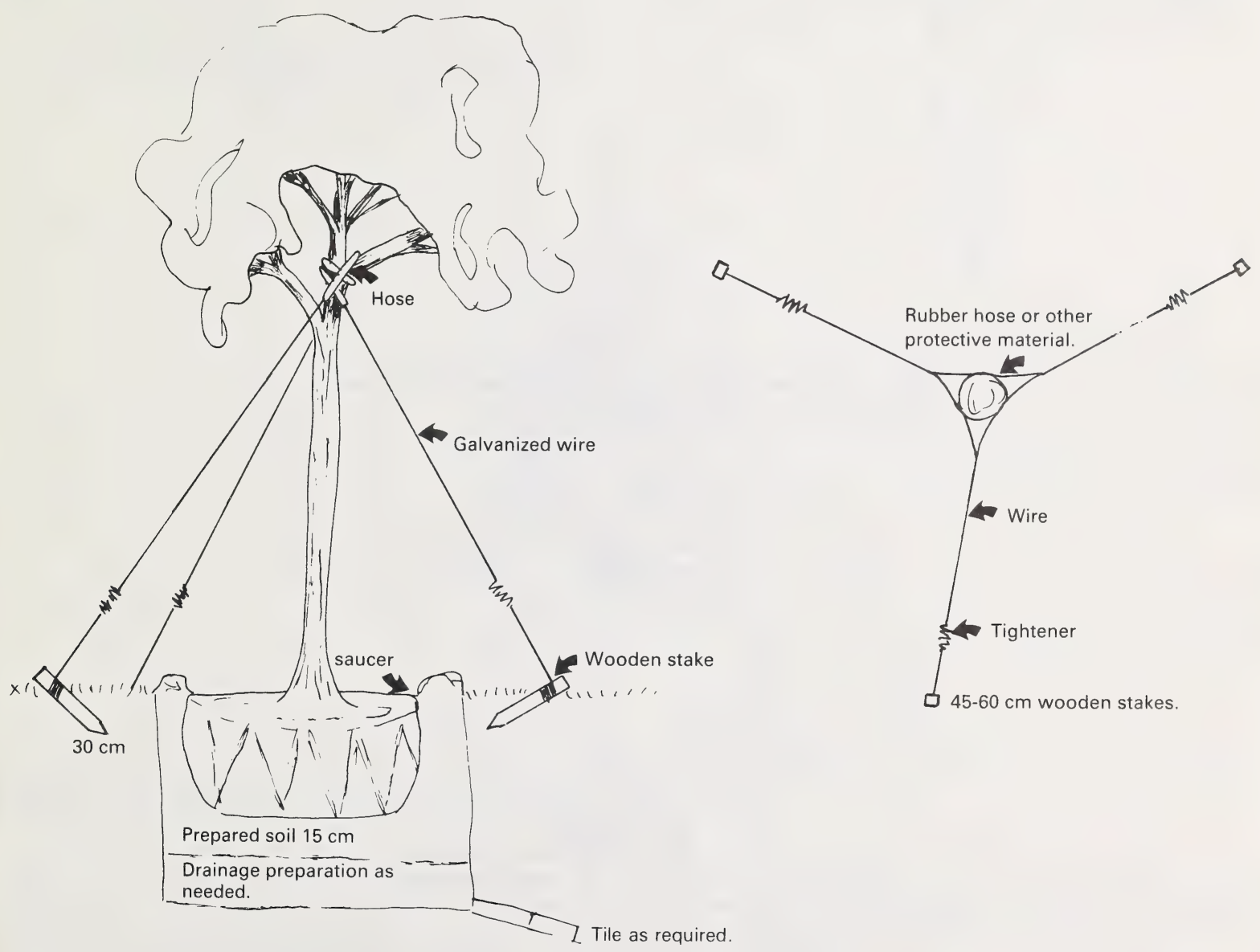

Figure 26. Trees over $6 \mathrm{~m}$ high planted in open areas can be supported with guy wires.

\section{Supporting}

All newly planted trees need some support and wiring to prevent wind damage.

The trees must be protected from the guy wires by rubber or leather bands or by short pieces of garden hose. Wires or cables must slope from halfway up the tree to the ground at about a 45 degree angle.

Guy wires or cables are rarely placed around trees set along the city streets or in public parks. Unless protected or plainly marked so as to be readily visible, especially at night, they are a constant source of danger to passersby. 

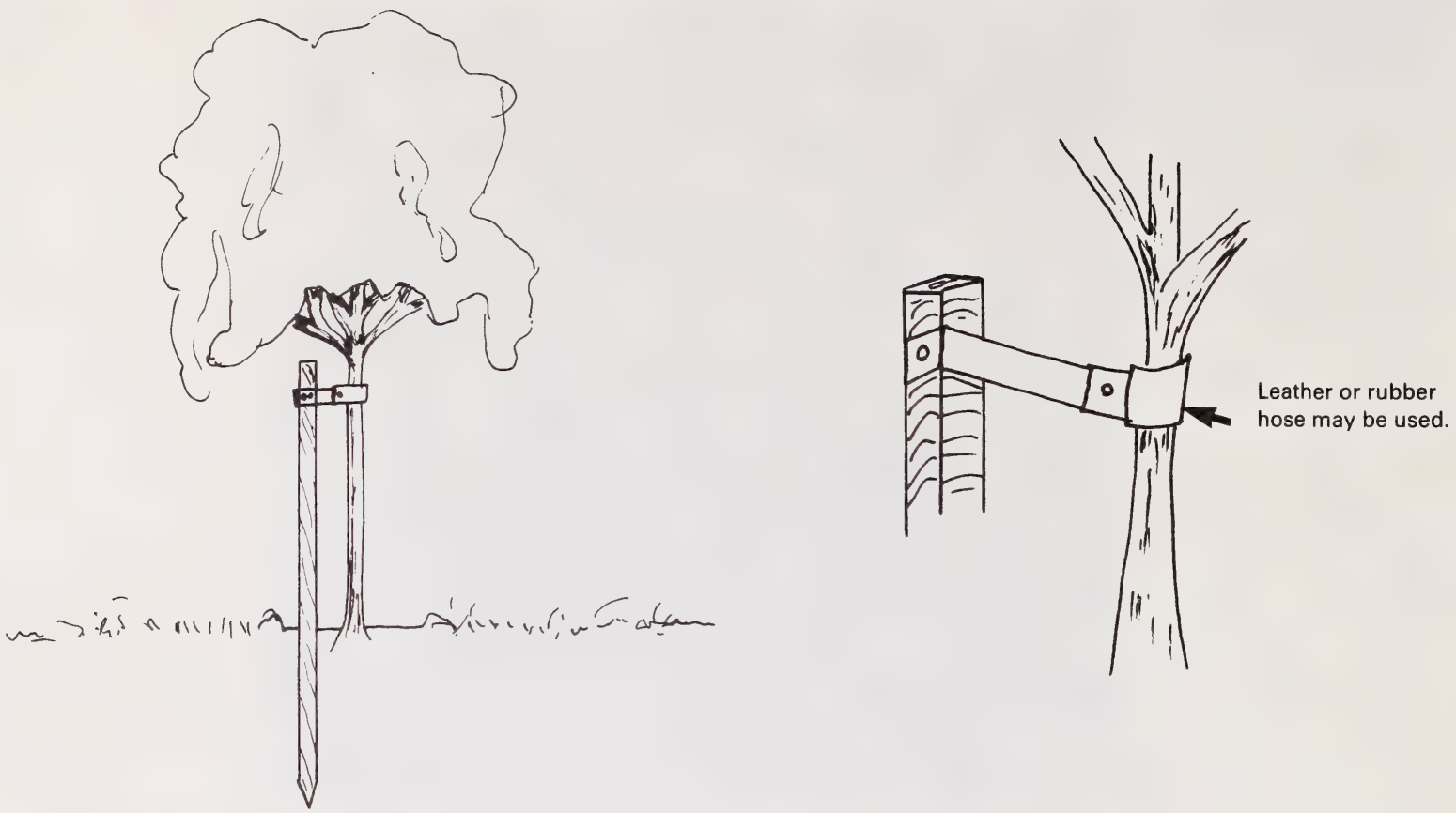

Figure 27. For trees under $6 m$ this method of supporting the newly transplanted tree is recommended.

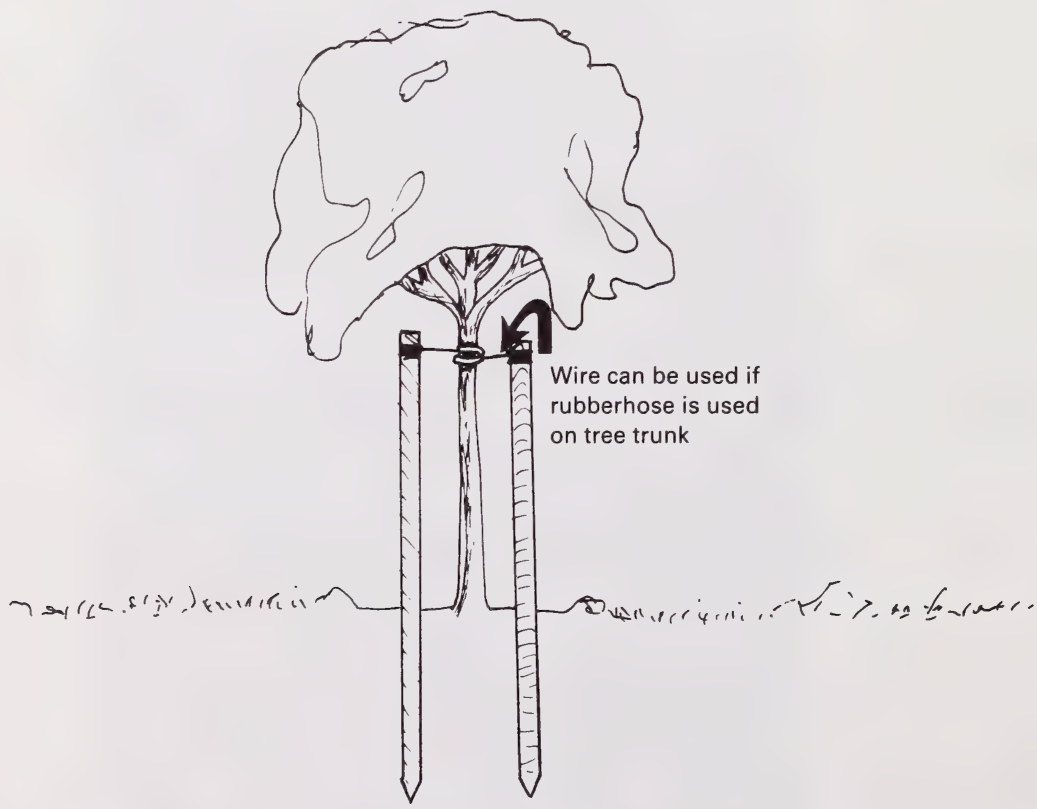

Figure 28. Supporting a tree with 2 stakes. 


\section{Pruning}

Most plants require some pruning before and after planting. The amount of pruning at planting time depends upon the species, the number of roots cut off in digging, and the maintenance it will receive during the establishment period.

The necessity of heavy pruning of transplanted trees is being questioned. In the past it was recommended that 20 to 30 percent of the branches be removed to help balance the top with the remaining root system. Some studies indicate that this practice may be detrimental in that it reduces the total leaf area and the subsequent food production capacity of the leaf canopy. Additional thinning of lateral branches should be limited or delayed until after one growing season. $(3,5)$

The amount of pruning depends not only on the condition of the tree but on the after care it is expected to receive. Less pruning is required when most of the roots remain.
Pruning should be confined to the secondary branches in order to maintain the natural shape of the tree. The growing tip of single-stemmed trees should never be cut back.

Broken, weak, and interfering branches should be removed. One section of a bad fork or a weak crotch should be removed at transplanting time unless it represents a large portion of the branch skeleton. It is best to wait at least 1 year after transplanting to remove a major branch. The terminal leader should not be pruned from a tree that normally grows from a central leader. If the terminal has been broken, prune back only as far as necessary to the next strong lateral twig or bud which will form the new terminal growth. All newly planted trees should be pruned to a single leader when transplanted unless a multiple leader is desired.

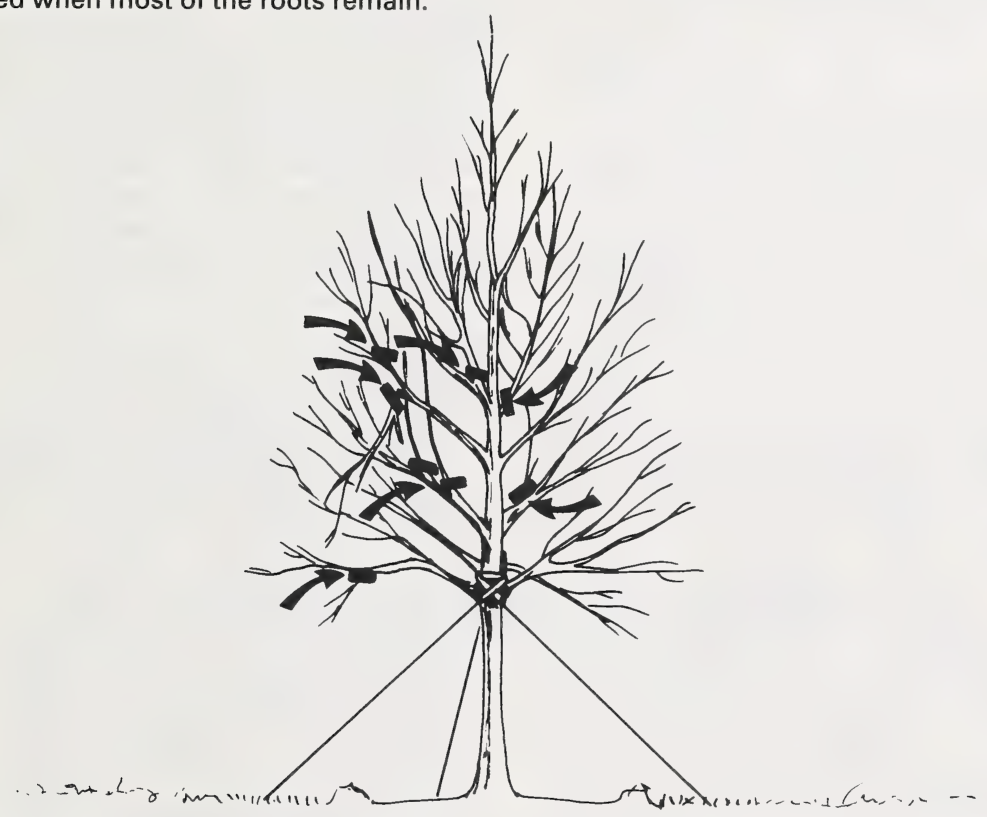

Figure 29. All broken, weak, and interfering branches should be removed at time of planting. Selective pruning may be necessary to maintain the typical form for the species. The black bars on the

Little or no pruning of evergreens is needed except to remove broken or severely injured branches.

Pruning should be restricted to 1 year old wood. Cutting into 2 year old wood should be avoided if possible.

The growth habit of evergeens will influence the pruning practices. Fir, pine, and spruce develop characteristic whorls of branches. Most of the growth occurs from closely placed buds near the end of the previous year's growth. It is not advisable to prune these evergreens since they have few if any latent buds. With large plants of this type, some branches can be removed to reduce transpiration.

For shrubs all injured, weak, interfering, and poorly placed branches should be removed at the time of planting. Pruning also may consist of removing older stems and shortening younger ones. Maintain a gradual renewal system when prun- branches indicate branches that should be removed on a newly planted tree.

ing, encourage new breaks from the base of the plant and remove older branches as necessary. Formalized pruning has been replaced by a more natural pruning that will maintain the natural growth habit.

The condition of the stock when received will largely determine the amount of additional pruning required. Nursery grown plants that have been well cared for and when properly dug will usually have a good root system and a well developed top. Such shrubs require less pruning. If there is evidence of dried or shriveled bark, the plant should be examined carefully to determine its potential for survival. Plants which have been stored over winter, regardless of optimum storage conditions, will seldom be in as good a condition as freshly dug stock. They should, therefore, be pruned more severely. The natural form of the plant should always be maintained. 
Many deciduous shrub species will form a new top and reestablish themselves more readily by cutting all stems down to 10 to $15 \mathrm{~cm}$ stubs. This may be desirable if maintenance after planting will be minimal. The height of cut-back should be carefully considered since many flowering shrubs are single stemmed or grafted plants. Large branches should be cut close to the parent branch or trunk. Any stubs left on large branches usually die back to the main branch. Small branches should be cut back to a bud.

The issue of whether or not to use tree wound dressings remains controversial. For many years tree wound dressings were considered beneficial and essential, especially on large wounds. Studies presented by Shigo (7) and other work by Neely (6) indicate that wound dressings are of little value and may only be cosmetic.

Rubbing alcohol, which is safe and noncorrosive to metal, is highly recommended for sterilizing all pruning tools.

\section{Watering}

The soil around the tree must not be allowed to dry out. The water must be allowed to penetrate slowly into the soil. Trees and shrubs benefit little from frequent, light watering but the soil should not be overwatered as this drives out oxygen.

Summer showers cannot be depended upon to supply sufficient moisture. An occasional good soaking with the hose is required. The soil ball must not be allowed to dry out the first growing season. Enough water must be applied to wet the entire soil area. The use of the Rex-Keyser method is recommended, the tubes should be filled completely, left to drain and filled again. (See Figure 30).

Frequent spraying of the needles of newly planted evergreens helps cut down on moisture loss from the needles but must be done on cloudy days. If tap water is applied to needles or leaves in sunny hot weather, the surface can be burned or otherwise injured. A pile of dirt is sometimes placed around the trunk to shed water and to prevent the homeowner from overwatering. This procedure should be avoided because: 1) the homeowner should be carefully advised as to how to water, 2) the mound of dirt prevents adequate watering of the ball, and 3 ) if the soil piled around the trunk is clay, this places a thick impervious layer over the ball. All excess soil taken from the hole should be removed at planting time and not left to be removed later.
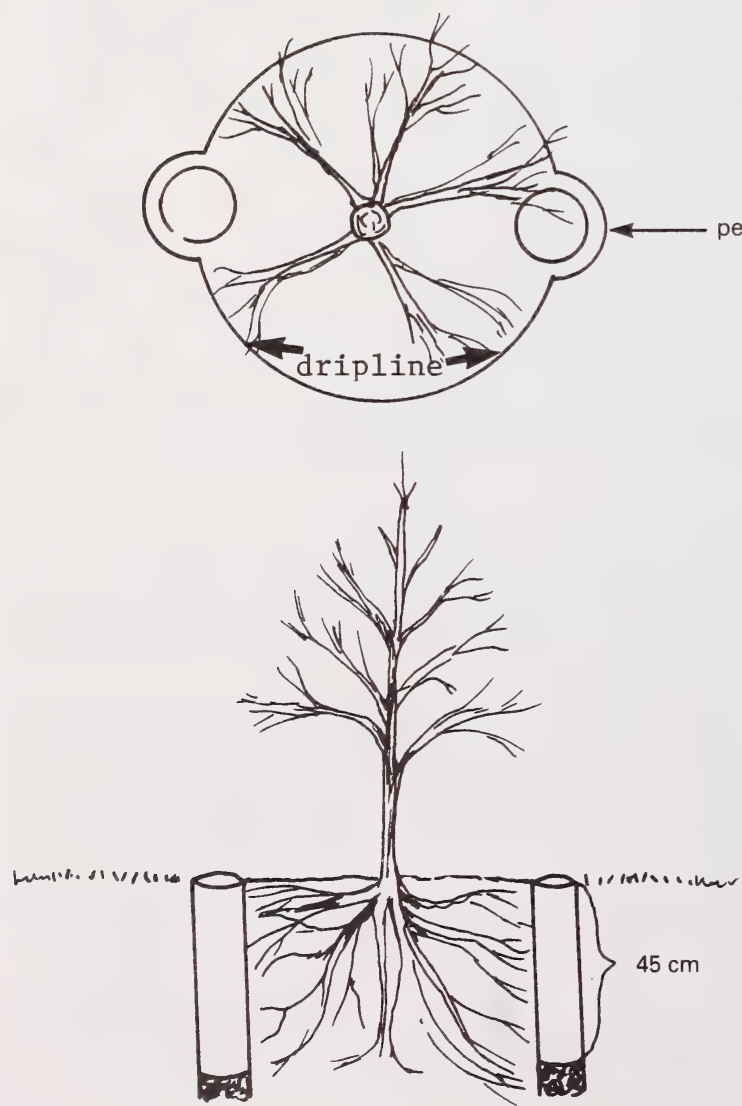

Use a sod plug to cover the perforated tube which is filled with gravel (e.g. $20 \mathrm{~mm}$ stone)

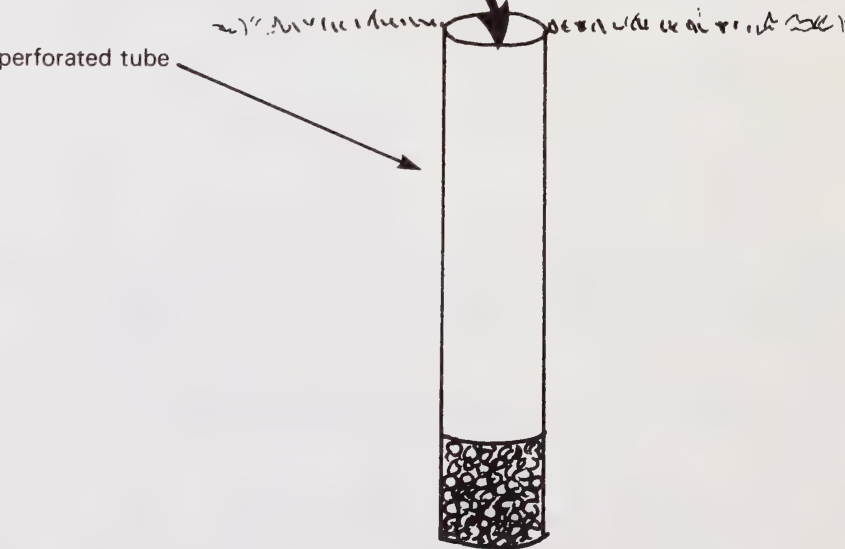

Figure 30. The diagrammatic sketch showing Rex-Keyser method for facilitating watering of newly planted trees: After the hole is dug, semi-circular areas are cut into the sides of the hole. Cylindrical cardboard tubes approximately $45 \mathrm{~cm} \times 7 \mathrm{~cm} \times .070 \mathrm{~cm}$ are inserted above a few centimetres of crushed rock or dolomitic limestone, with the upper ends flush with the soil surface. The tubes are filled with crushed stone and the top of the tubes covered until the tree is planted in the normal manner. The lower sketch presents a cross section of the completed installation. 


\section{Bark Protection}

The trunk and branches of newly planted thin-barked trees and trees that may not receive regular watering after planting should be protected with tree wrapping paper.

Wrapping reduces excessive water loss and drying of the bark, protects the bark from sunscald, and prevents attack by bark borers. The wrapping is started at the base of the trunk and slightly below the soil level. Carefully replace the soil around the trunk. Overlap each spiral turn $1 / 4$ to $1 / 3$ the width of the strip. The spiral wrapping should be continued up to the branches and large lower branches should be wrapped a few feet beyond the trunk.

The wrapping is secured by 2-ply twine, starting at the top with a looped slip knot and proceeding downward with an overhand loop every 10 to $15 \mathrm{~cm}$.

A cardinal rule is never to use nylon cord anywhere on a tree. It will girdle if not removed in time. Examine the wrapping periodically and loosen the cord as necessary to prevent girdling. The wrapping is often left in place until it begins to deteriorate. Paper may last for 2 years.

It is often a wise procedure to remove the paper after the first year and examine the trunk for possible borer activity and canker formation.

\section{Mulching}

Mulching newly planted evergreens is again becoming a common practice. Mulches prevent wide fluctuations in soil temperature, keep the soil warmer and help to conserve moisture.

Newly planted trees taken from the wild should be mulched to a depth equal to that found in its native location.

The mulch can be wood chips, peat moss, sawdust, partially decomposed leaves or other organic materials. A 5 to $6 \mathrm{~cm}$ deep layer of mulch over the entire root area is recommended.

When applied following fall planting, the mulch will maintain a more favorable temperature for root growth. It should not be applied to plants in early spring until after the soil has warmed, otherwise it will delay soil warming by 2 weeks or longer. Many evergreens grow better in a cool soil during the hot summer months, and a good mulch applied in late spring or early summer will help maintain this condition.

Sand is sometimes used as a mulch in the depressed area around small newly planted trees along streets. Water is thus absorbed more rapidly and is held longer.

\section{ANTI-TRANSPIRANTS}

Loss of water from needles and leaves can be partly overcome with an anti-transpirant such as Wilt-Pruf ${ }^{\text {IN }}$ and Foli-guard $^{\mathrm{TN}}$. These products are a liquid plastic which is diluted in water and then applied over the leaves and stems with a pressure sprayer. It dries in about 20 minutes to form a film that permits the exchange of gases but inhibits the passage of water vapor, thus reducing the loss of water from the leaves. Treated trees become more easily established but they still require watering albeit less frequently.

Anti-transpirants help assure more successful transplanting but their use must not be a substitute for good gardening practices.

Carelessly handled trees and those with poor root systems will not survive the transplanting shock nearly as well as those that are properly handled and have an adequate root system.

\section{TRANSPLANTING WITH A TREE SPADE}

A number of well-designed and efficient tree-moving machines are now on the market. These are used mainly by commercial arborists, park superintendents, and others who move large trees. The machines are of two distinctly different types. The trailer types have 2, 6, or 8 wheels, and are drawn by trucks or tractors. Many of the trailer types of tree movers are designed to carry most of the weight on the rear wheels, the soil ball of the tree resting on a cradle just ahead of these wheels. The front wheels balance and guide the trailer. The automotive types of tree movers are mounted on trucks or tractors. At least five different types are in common use. The tree with some soil is lifted out of the hole, moved to the new site, and set into a previously dug receiving hole.

Using mechanical equipment for digging and transporting plants saves time, reduces manpower, and may be less expensive. Both in purchase and maintenance, the tree spades are expensive and require the moving of many trees during a year to make them economically feasible.

One advantage in using the tree spade is that it permits the moving of larger trees, thus reducing loss due to vandalism and accidents that smaller diameter bare-root trees are prone to. Another advantage is the instant landscape effect. (2)

Soil type, plant species and the environment must be considered when determining the method of transplanting.
One major disadvantage of tree spades is the polishing effect it has on the soil in the new hole. This has been shown to reduce root penetration and may cause water build up resulting in root deterioration.

It is important to know the size limitation of the machine being used and not to attempt to move trees or shrubs larger than the machine can adequately handle.

The size requirement of the soil ball for various tree sizes must be rigidly adhered to. (See tables on ball sizes)

The planting of large trees with a tree spade reduces the transplanting shock mainly during the year of transplanting. (9) Careful handling of plant material is necessary to assure successful establishment of transplanted trees and shrubs. Persons operating the equipment must receive proper maintenance and operating instructions from the manufacturer's representative.

It is extremely important to centre the tree in the digging spade; this will maximize the number of roots taken. It is recommended that the machine is settled level and flat on the ground when digging the new hole. When digging the plant it is advisable to level the bottom of the machine 5-10 $\mathrm{cm}$ above the ground. This allows the plant to be placed somewhat deeper in the hole; it also prevents the plant from being planted higher than the surrounding ground. 


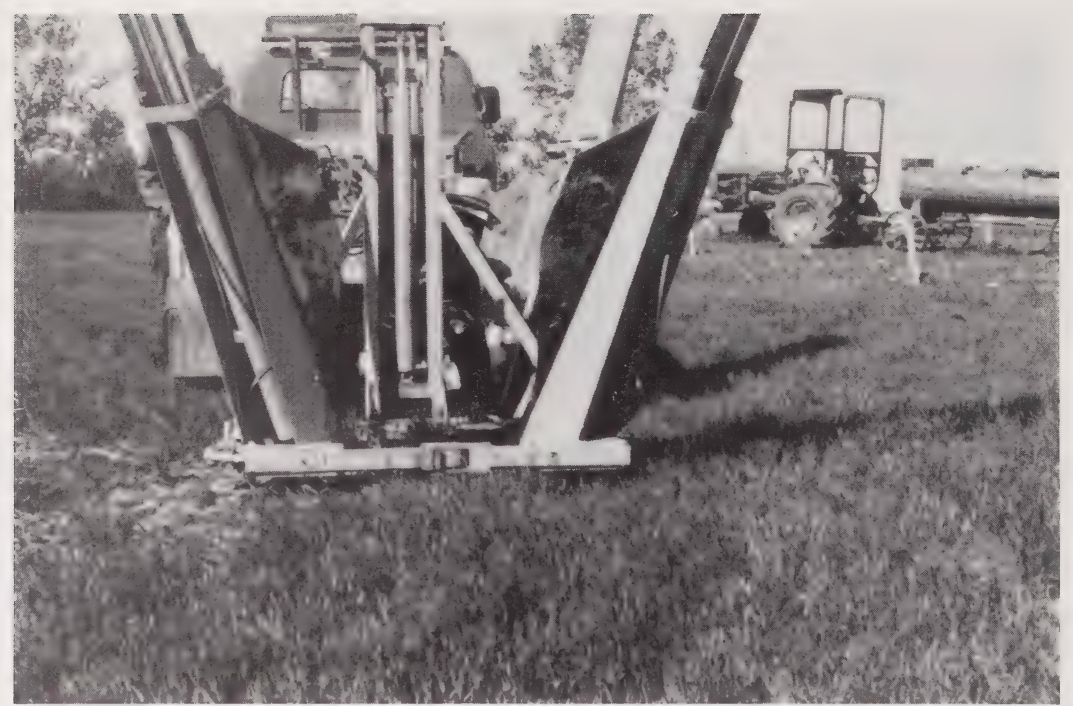

Figure 31. Setting the spade on new hole site. Frame must be as level as possible and as close to the ground as possible.

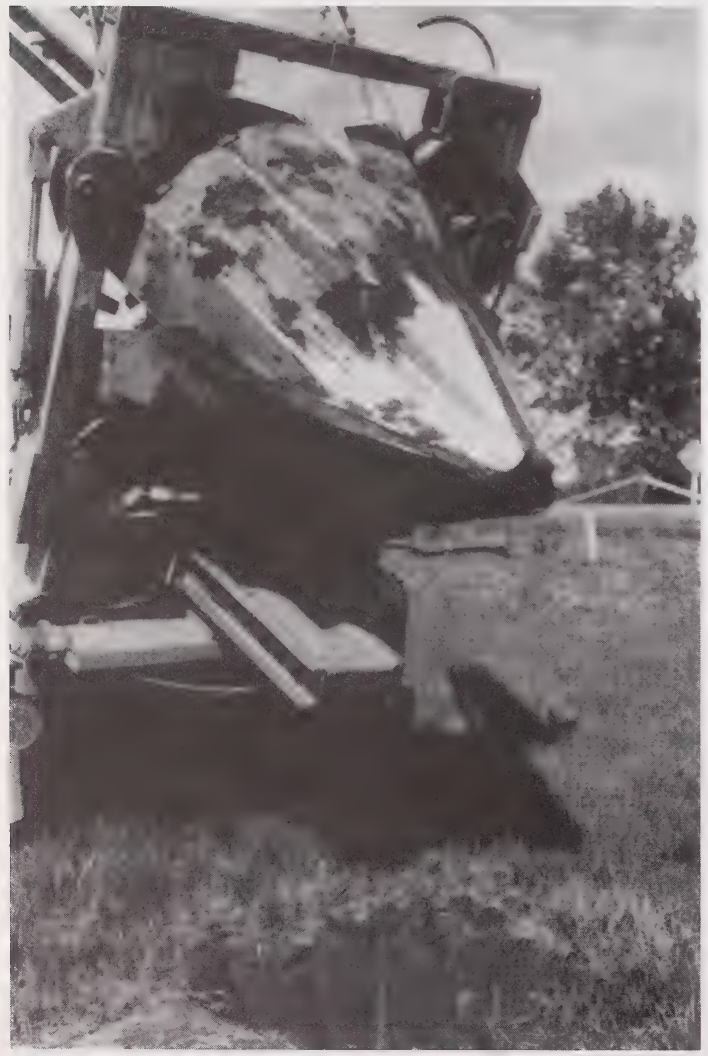

Figure 32. Shiny soil surface must be broken up once soil cone is removed.

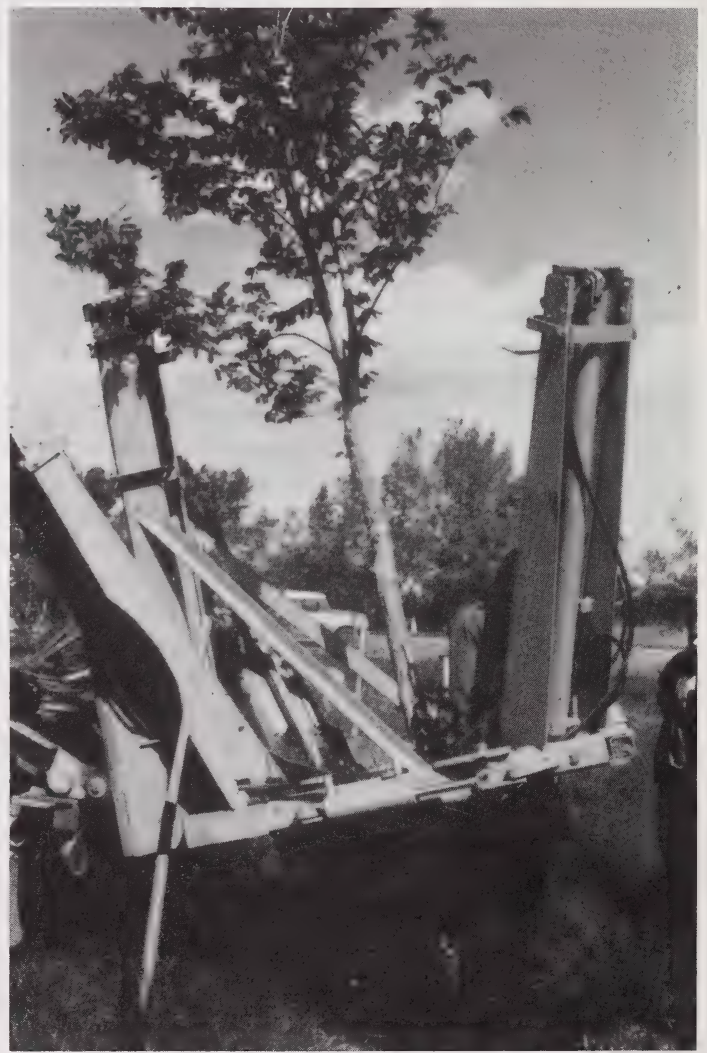

Figure 33. The tree must be centred in blades. The frame must be set level and $5-10 \mathrm{~cm}$ above ground. 


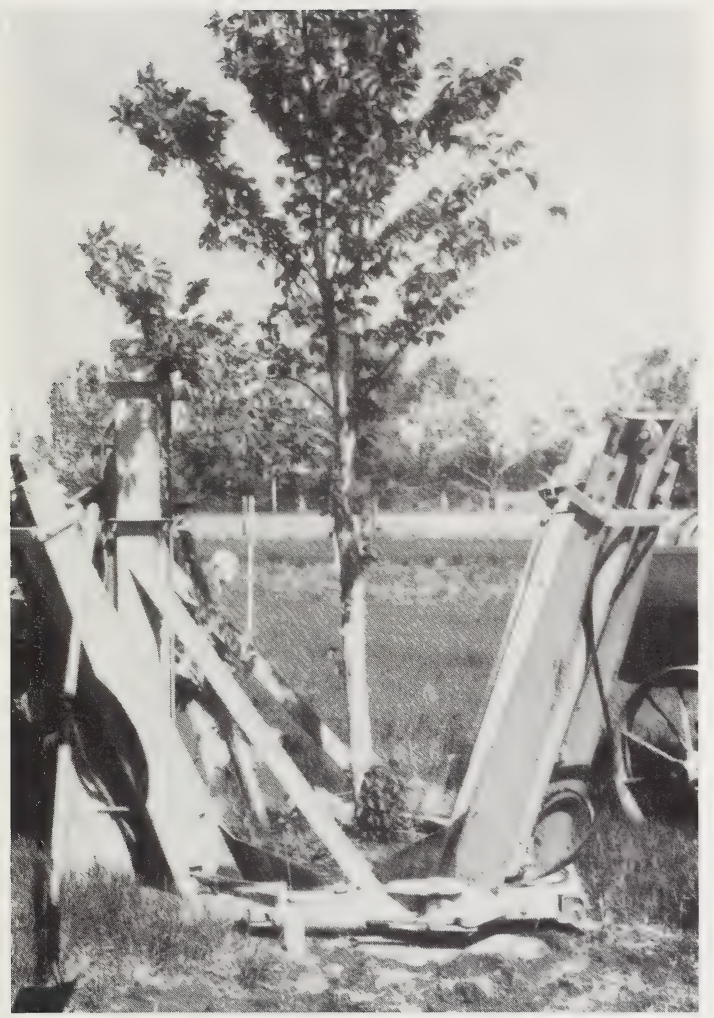

Figure 34. Planting into new hole. The tree must be as straight as possible, centred into new site.

Opposite blades are inserted to equal depths before proceeding to insert the remaining blades to the same depth. Haphazard insertion of blades will result in a lopsided ball that will not permit the tree to be planted vertically in the planting hole.

The preferred method when machine digging is to dig the new hole by hand or with a back hole. This prevents glazing of the sides. If a spade is used and a glossy surface results, a hand spade can be used to break up the crust.

Once the digger has been safely moved out of position, minor vertical alignment and adjustment of the soil ball can be made. Hand alignment should be done with the utmost care to avoid cracking the soil ball and damaging the roots.

The tree should be staked and cabled to avoid tilting or movement of the soil ball if considerable backfill is required.

Guy the tree properly before watering and filling in the hole, 3 or 4 wires should be used and the guys should remain on the tree for at least 2 years. If the tree species is known to recover slowly from transplanting, or when poor soil conditions exist, the supports should remain for 3 years or more.

After guying, the hole is filled with a good friable soil. Using a hand spade, work the loose soil into the hole while flooding with water to make sure that all air pockets are eliminated. With large balls the fill should be carefully

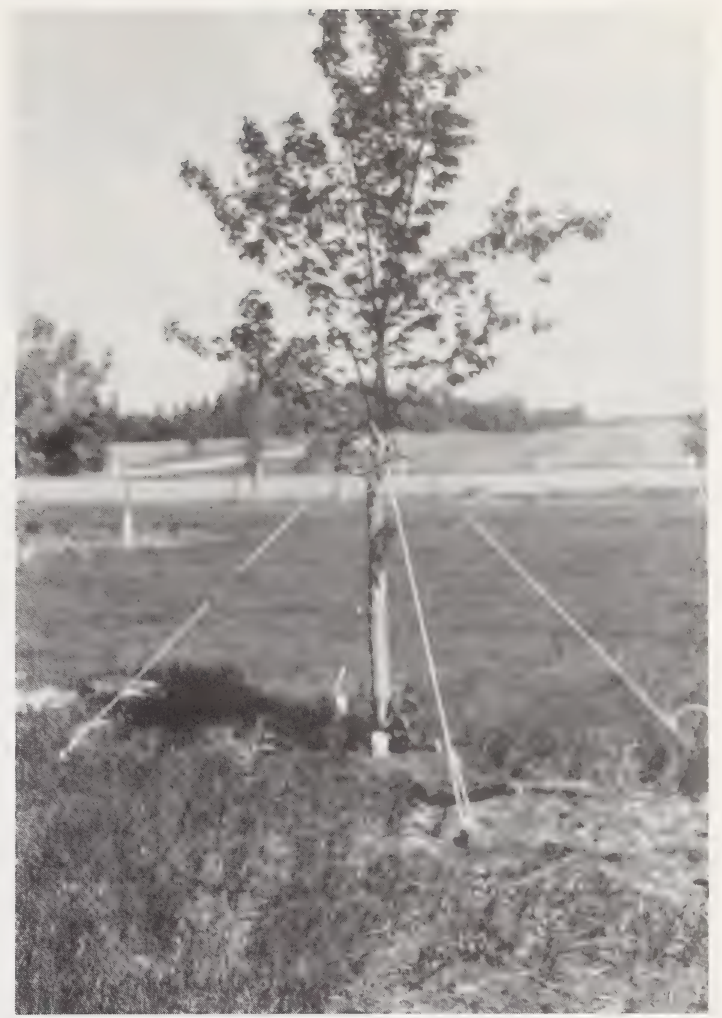

Figure 35. Guying and securing.

tamped for the first one-third to one-half of the hole depth before adding water and additional soil. The tamping will stabilize the ball and prevent the ball from tipping during strong winds.

The trees to be moved by machine will probably be over $1.5 \mathrm{~m}$ in height while the upper limit could be over $8 \mathrm{~m}$. The goal of transplanting is always survival of the transplanted specimen. Choosing too large a tree for the size of the transplanting machine can be a major cause of failure of survival.

Table 4 lists the most common tree species transplanted in Alberta with their maximum desirable height at time of transplanting.

The most opportune season for transplanting both evergreens and deciduous trees is in early spring. This means the time after frost has disappeared from the subsoil and before the buds break. Usually this period is short (3-4 weeks).

The next best season for transplanting evergreens is from August 15 till freeze-up, and for deciduous trees after September 1. The operation should not go on too long into the fall owing to the possibility of overwintering losses in Alberta's cold winters. A period of 6 weeks following transplanting should be allowed for settling. This will also reduce frost heaving.

July is usually the hottest month in Alberta, transplanting during this time should be avoided or done at considerable risk. 


\begin{tabular}{lr}
\hline SPECIES NAME & $\begin{array}{c}\text { MAXIMUM SIZE FOR } \\
\text { TRANSPLANTING (metres) }\end{array}$ \\
\hline $\begin{array}{l}\text { EVERGREENS } \\
\text { Pinus contorta latifolia (Lodgepole pine) } \\
\text { Pinus sylvestris (Scots pine) }\end{array}$ \\
Picea glauca (White spruce) & 3.0 \\
Picea pungens glauca (Colorado spruce) & 3.0 \\
DECIDUOUS & 4.5 \\
Malus sp. (Fruiting crabapples) & 4.5 \\
Malus sp. (Flowering crabapples) & \\
Malus sp. (Apples) & 3.0 \\
Sorbus americana (Mountain ash) & 3.5 \\
Quercus macrocarpa (Bur oak) & 3.5 \\
Fraxinus pensylvanica subintegerrima (Green ash) & 3.5 \\
Prunus padus commutata (Mayday) & 4.0 \\
Prunus virginiana var. (Chokecherry) & 4.5 \\
Crataegus sp. (Hawthorn) & 4.5 \\
Larix sibirica (Siberian larch) & 4.5 \\
Betula sp. (Birch) & 4.5 \\
Ulmus americana (American elm) & 6.0 \\
Ulmus pumila (Siberian elm) & 6.0 \\
Acer negundo (Manitoba maple) & 6.0 \\
Eleagnus angustifolia (Russian olive) & 6.0 \\
Populus sp. (Poplars) & 6.0 \\
Salix sp. (Willows) & 6.0 \\
\hline
\end{tabular}

* From H. T. Oosterhuis

Transplanting large shrubs such as lilac, honeysuckle, dogwood, caragana, elder, saskatoon or similar plants is not recommended. These shrubs will quickly grow into mature specimens from small transplants.

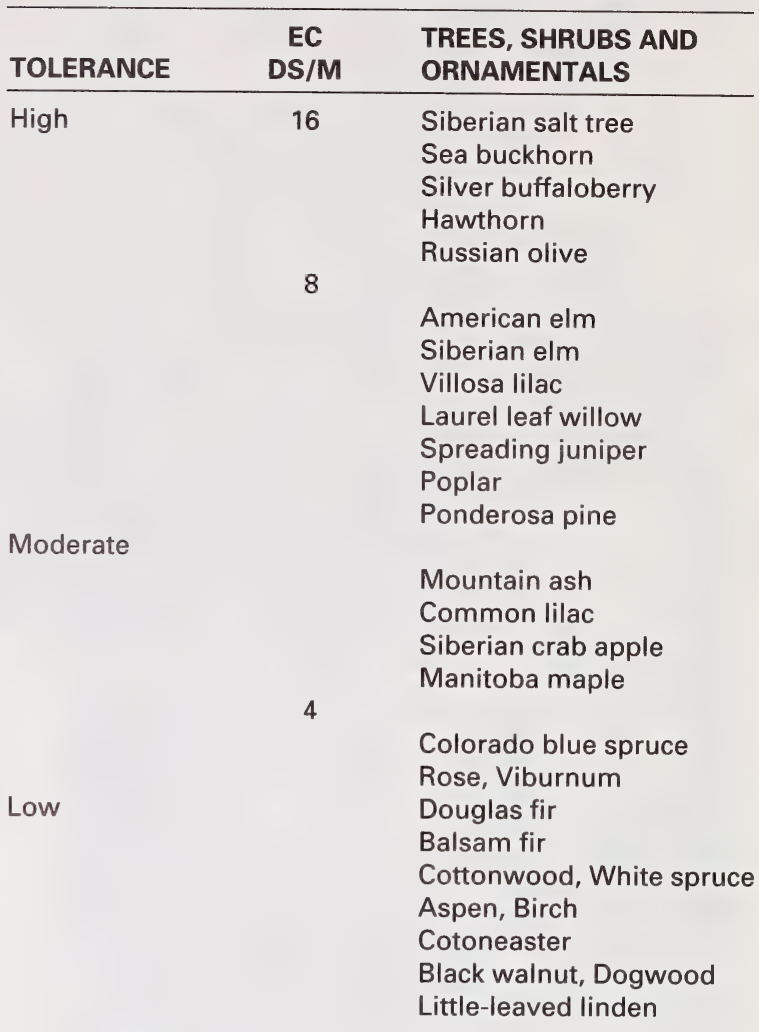

\section{WHY THEY FAIL}

Digging with mechanical tree spades limits the ball size to the size of the machine. Digging trees too large for the machine results in a soil ball that does not contain a sufficient number of roots for successful recovery after transplanting. Transplanting failures then result from poor judgment, not from tree spade failure.

Close examination of the roots of mechanically-dug trees that fail to survive sometimes indicates that the roots have been shredded and split. These roots die back several inches from the cut ends. Failure to keep the cutting edge of the blades sharpened often accounts for this damage. In other cases, the soil ball contains larger, older roots and few small finely-branched roots. Limited regeneration of roots out of the ball may indicate that too few roots were moved and the tree died from moisture stress.

Mechanical tree spades are tools that offer great potential when used properly. There are limitations, however, particularly in transporting trees long distances.

Good judgment and proper use of the machine must be stressed. Dead trees are a credit to no one.

\section{SELECTED BIBLIOGRAPHY}

(1) Carter, J. Cedric. 1970 Illinois Trees: Selection, planting, and care. Illinois Natural History Survey Circular 51. 123 pp.

(2) Cool, R. A. 1976. Tree Spade vs. Bare-Root Planting. J. Arboric. 2(5): $92-95$.

(3) Giles, F. A. \& W. B. Siefert. 1971. Pruning Evergreens \& Deciduous Trees and Shrubs. University of Illinois, College of Agriculture Cooperative Extension Service Circular 1033. 58 pp.

(4) Himelich, E. B. 1981. Tree \& Shrub Transplanting Manual. International Society of Arboriculture. 76 pp.

(5) National Arborist Association. 1970. Pruning Standards for Shade Trees. National Arborists Association. 12 pp.
(6) Neely, D. 1970. Healing of Wounds on Trees. J. American Society for Horticulture Science. 95:536-540.

(7) Shigo, Alex L. \& Charles L. Wilson 1977. Wound Dressing on Red Maple and American Elm. Effectiveness After Five Years. J. Arboric. 3(5): 81-87.

(8) Shoup, S., R. Reavis, \& C. E. Whitcomb, 1980. Effects of Pruning \& Fertilizers on Establishment of Bareroot Deciduous Trees 1978, 79, 80. Agricultural Experiment Station, Oklahoma State University, Research Report P-803:5-7.

(9) Vanstone, D. E. \& W. G. Ronald. 1981. Comparison of BareRoot Versus Tree Spade Transplanting of Boulevard Trees. J. Arboric. 7(10): 271-274. 



